\title{
Successive DNA extractions improve characterization of soil microbial communities
}

\author{
Mauricio R. Dimitrov Corresp., ${ }^{1,2}{ }^{\text {， Annelies J. Veraart }}{ }^{1}$ ， Mattias de Hollander ${ }^{1}$ ， Hauke Smidt ${ }^{2}$, Johannes A. van \\ Veen $^{1}$, Eiko E. Kuramae ${ }^{1}$ \\ 1 Department of Microbial Ecology, Netherlands Institute of Ecology, Wageningen, Netherlands \\ 2 Laboratory of Microbiology, Wageningen University, Wageningen, Netherlands \\ Corresponding Author: Mauricio R. Dimitrov \\ Email address: M.Dimitrov@nioo.knaw.nl
}

Currently, characterization of soil microbial communities relies heavily on the use of molecular approaches. Independently of the approach used, soil DNA extraction is a crucial step, and success of downstream procedures will depend on how well DNA extraction was performed. Often, studies describing and comparing soil microbial communities are based on a single DNA extraction, which may not lead to a representative recovery of DNA from all organisms present in the soil. The use of successive DNA extractions might improve soil microbial characterization, but the benefit of this approach has only been limitedly studied. To determine whether successive DNA extractions of the same soil sample would lead to different observations in terms of microbial abundance and community composition, we performed three successive extractions, with two widely used commercial kits, on a range of clay and sandy soils. Successive extractions increased DNA yield considerably (1-374\%), as well as total bacterial and fungal abundances in most of the soil samples. Analysis of the $16 \mathrm{~S}$ and $18 \mathrm{~S}$ rRNA genes using 454-pyrosequencing, revealed that microbial community composition (taxonomic groups) observed in the successive DNA extractions were similar. However, successive DNA extractions did reveal several additional microbial groups. For some soil samples, shifts in microbial community composition were observed, mainly due to shifts in relative abundance of a number of microbial groups. Our results highlight that performing successive DNA extractions optimize DNA yield, and can lead to a better picture of overall community composition. 
1 Successive DNA extractions improve characterization of soil

2 microbial communities

3

4 Mauricio R. Dimitrov ${ }^{1,2^{*}}$, Annelies J. Veraart ${ }^{2}$, Mattias de Hollander ${ }^{2}$, Hauke Smidt ${ }^{1}$,

5 Johannes A. van Veen ${ }^{2}$, Eiko E. Kuramae ${ }^{2}$

6

$7 \quad{ }^{1}$ Laboratory of Microbiology, Wageningen University, Wageningen, the Netherlands.

$8{ }^{2}$ Department of Microbial Ecology, Netherlands Institute of Ecology NIOO-KNAW,

9 Wageningen, the Netherlands.

10

11 * Corresponding author

12 Mauricio R. Dimitrov

13 Phone: +31317 473496

14 Email:m.dimitrov@nioo.knaw.nl

15 Postal address: the Netherlands Institute of Ecology (NIOO-KNAW),

16 Droevendaalsesteeg 10, 6708 PB, the Netherlands. 
17 Abstract

18 Currently, characterization of soil microbial communities relies heavily on the use of 19 molecular approaches. Independently of the approach used, soil DNA extraction is a 20 crucial step, and success of downstream procedures will depend on how well DNA 21 extraction was performed. Often, studies describing and comparing soil microbial 22 communities are based on a single DNA extraction, which may not lead to a 23 representative recovery of DNA from all organisms present in the soil. The use of 24 successive DNA extractions might improve soil microbial characterization, but the 25 benefit of this approach has only been limitedly studied. To determine whether 26 successive DNA extractions of the same soil sample would lead to different 27 observations in terms of microbial abundance and community composition, we performed three successive extractions, with two widely used commercial kits, on a range of clay and sandy soils. Successive extractions increased DNA yield considerably (1-374\%), as well as total bacterial and fungal abundances in most of 31 the soil samples. Analysis of the $16 \mathrm{~S}$ and $18 \mathrm{~S}$ rRNA genes using 45432 pyrosequencing, revealed that microbial community composition (taxonomic groups) 33 observed in the successive DNA extractions were similar. However, successive DNA 34 extractions did reveal several additional microbial groups. For some soil samples, 35 shifts in microbial community composition were observed, mainly due to shifts in relative abundance of a number of microbial groups. Our results highlight that performing successive DNA extractions optimize DNA yield, and can lead to a better picture of overall community composition. 
40 Microorganisms are key to various biogeochemical processes that drive life on Earth

41 (Falkowski et al., 2008). Soil is one of the most diverse biomes found on Earth and a 42 large reservoir of microbial diversity (Bardgett and van der Putten, 2014; Gans et al., 43 2005; Torsvik et al., 1990; Torsvik et al., 2002). Besides being essential drivers of 44 biogeochemical processes, soil microorganisms also play an important role in 45 processes such as plant nutrition (Mendes et al., 2013), disease suppression 46 (Mendes et al., 2011), bioremediation (Maphosa et al., 2012), global warming 47 mitigation (Bender et al., 2014), to just name a few. However, understanding the 48 mechanisms behind all these processes is not an easy task, since the vast majority 49 of microorganisms are still unculturable (Hawksworth and Rossman, 1997; Torsvik 50 and Øvreås, 2002). The introduction of culture independent methodologies has 51 revolutionized the way soil microbial communities are studied. Extracting and 52 characterizing DNA has become ordinary in most soil microbial ecology studies 53 (Delmont et al., 2012; Navarrete et al., 2015; Pan et al., 2014; Tahir et al., 2015). 54 Moreover, constant improvements and accessibility of high throughput sequencing 55 technologies have allowed researchers to characterize soil microbial communities in 56 an unprecedented way and at ecologically relevant scales and resolution of time, space and environmental conditions.

58 Due to its stability, DNA is often the nucleic acid of choice to be used to characterize 59 microbial communities in soils. Once extracted, DNA can be used in a range of 60 experiments that may provide insights with respect to the abundance, diversity and 61 functional potential of soil microbial communities. Therefore, successful 62 characterization of soil microbial communities is directly dependent on the quality of 63 the DNA extracted from such soil sample. With the introduction of culture 64 independent methodologies to study soil microbial communities, a variety of soil DNA 65 extraction protocols have been developed (Berry et al., 2003; Burgmann et al., 2001; 66 Liles et al., 2008; Robe et al., 2003; Zhou et al., 1996). However, DNA extraction 67 from soil can be laborious and problematic (Braid et al., 2003; Dong et al., 2006; 68 Frostegard et al., 1999; Robe et al., 2003). Often, as an alternative to simplify and 69 standardize procedures, commercial DNA extraction kits are used. Comparison of 70 different soil DNA extraction protocols, including commercial kits, has shown that 71 DNA yield and purity varies greatly depending on the protocol and soil type 72 (Burgmann et al., 2001; Inceoglu et al., 2010; Knauth et al., 2013). Therefore, every 73 DNA extraction protocol has its own bias, and it will yield DNA that is representative 74 of a portion of the microbial community present in the original soil sample (Delmont 
75 et al., 2011). Feinstein et al. (2009) analysed DNA extraction efficiency of a

76 commonly used commercial soil DNA extraction kit, and indicated that not all

77 microbial DNA present in a soil sample is extracted with a single DNA extraction.

78 When soil DNA, from successive DNA extractions performed on a single sample,

79 was used to characterize microbial communities, substantial shifts in the bacterial

80 community were observed. Although the findings of Feinstein et al. (2009) were

81 published more than seven years ago, less than $15 \%$ of recently published studies

82 have used multiple DNA extractions when characterizing soil microbial communities

83 (Figure S1). Here, to investigate further how bias of incomplete soil DNA extraction

84 may affect microbial characterization, we expanded on the reported findings by

85 Feinstein et al. (2009). Two widely used commercial soil DNA extraction kits were

86 used to extract DNA from a variety of soils. Successive DNA extractions were

87 performed on six different soils collected throughout the Netherlands, and bacterial

88 and fungal abundances, as well as community diversity and composition of each

89 successive extraction, were assessed by using next generation technology

90 sequencing of $16 \mathrm{~S}$ and $18 \mathrm{~S}$ ribosomal RNA ( $\mathrm{RRNA}$ ) gene amplicons. 


\section{$91 \quad$ Material and Methods}

\section{Manuscript to be reviewed}

\section{Soil samples}

Soil samples as well as sampling procedure used in the present work have been described previously (Kuramae et al., 2012). Soil cores $(8 \mathrm{~cm}$ of diameter and $30 \mathrm{~cm}$ deep) were sampled in six contrasting fields located in different regions throughout the Netherlands (Figure S2). Briefly, a central sampling point and four other points, located $20 \mathrm{~m}$ from the central point, were chosen in each field, which resulted in five sample points per field (i.e. A, B, C, D and E). Each individual sample was composed of five subsamples (i.e. $A 1, A 2, A 3, A 4, A 5 ; B 1, B 2, B 3$, etc.), which were taken randomly within a two-meter radius in each sample point $(A, B, C, D$ and $E)$. Equal amounts of the five subsamples were pooled to obtain a single sample per sampling point (A, B, C, D and E), resulting in five biological replicates per field. Soil samples were chosen to represent five of the most important land management practices in the Netherlands (conventional and organic arable field, pasture, pine and deciduous forest). Moreover, soil samples were chosen and separated according to sand and clay content, resulting in two different soil classes: 'sandy' and 'clay' (Table S1). After sampling, samples were stored at $-80 \stackrel{\circ}{\mathrm{C}}$ until further processing.

\section{DNA extraction and quantification}

Soil DNA was extracted from each soil sample using two different commercial kits, which are widely used for such purpose (Kuramae et al., 2012; Martin-Laurent et al., 2001; Mendes et al., 2014; Sutton et al., 2013). Three replicates were extracted from each soil sample. The PowerSoil DNA isolation kit (MoBio Laboratories, Carlsbad, CA, USA) and the FastDNA Spin kit for soil (MP Biomedicals, Solon, OH, USA) were used according manufacturer's instructions. The bead-beating step of the PowerSoil DNA isolation kit (PS) was done at $5.5 \mathrm{~m} \mathrm{~s}^{-1}$ for $10 \mathrm{~min}$, using a Retsch MM301 mixer mill (Retsch $\mathrm{GmbH}$, Haan, Germany). Samples extracted with the FastDNA Spin kit for soil (FS) were processed using a FastPrep24 instrument (MP Biomedicals). For both kits, an initial DNA extraction was followed by a successive extraction, which was then followed by another extraction after samples had been stored overnight at $20 \stackrel{\circ}{ }{ }^{\circ}$ (Figure 1). Therefore, three DNA extractions were performed on three replicates of the six soil samples, resulting in nine DNA extracts per soil and extraction kit. After the bead-beating step of the first extraction (E1), tubes containing beads and soil were kept on ice until extraction had been finished. To start the second extraction (E2), while using PS, solution from new PowerBead tubes, without beads, was added to PowerBead tubes used in the first extraction, which still 
126 contained soil and beads. After that, DNA extraction proceeded exactly in the same

127 way as for E1. After the bead-beating step of E2, tubes containing beads and soil

128 were store overnight at $-20^{\circ} \mathrm{C}$. The third and final extraction (E3) was performed as

129 described for E1 and E2. The procedure described for PS was also used for FS;

130 when initiating a new DNA extraction sodium phosphate buffer and MT buffer were

131 added to the lysis matrix tubes containing beads and soil. Volumes of added buffers

132 were always in line with manufacturer's instructions. Extraction proceeded normally

133 afterwards. Supernatant recovery, throughout the whole DNA extraction procedure,

134 was done carefully in order to obtain a complete recovery and minimize carryover of

135 DNA from one extraction to another. When higher volumes of supernatant were

136 recovered, compared to manufacturer's instructions, adjusted volumes of solutions

137 were used in order to maintain the proper concentration of reagents. Total DNA

138 quantity and quality were measured using a Qubit 2.0 fluorometer (Life Technologies,

139 Carlsbad, CA, USA) and a NanoDrop 1000 spectrophotometer (Thermo Scientific,

140 Wilmington, DE, USA), as well as visualized on $1 \%(\mathrm{w} / \mathrm{v})$ agarose gel under UV light

141 after staining with ethidium bromide. Tris-acetate-EDTA (TAE) buffer was used for

142 gel preparation and electrophoresis.

\section{Bacterial and fungal abundances}

144 Quantitative real time PCR ( $\mathrm{PPCR}$ ) was used to determine total bacterial and fungal 145 abundances in each soil sample by targeting the 16S and 18S rRNA genes, 146 respectively. Quantitative PCR reactions were performed in a 384-well plate (Bio147 Rad, Hercules, CA, USA) using a CFX384 Real-Time PCR Detection system (Bio$148 \mathrm{Rad})$. All samples were analysed in triplicate, and reactions were carried out in a total 149 volume of $10 \mu \mathrm{L}$. qPCR reactions were prepared using $5 \mu \mathrm{L}$ of iQ SYBR Green super $150 \mathrm{mix}$ (Bio-Rad), $0.4 \mu \mathrm{L}$ of forward and reverse primers $(10 \mu \mathrm{M}), 0.1 \mu \mathrm{L}$ of Bovine 151 Serum Albumin $(20 \mathrm{mg} / \mathrm{mL}$ ), $0.1 \mu \mathrm{L}$ of VisiBlueTM qPCR mix colorant (TATAA 152 Biocenter, Gothenburg, Sweden) and $4 \mu \mathrm{L}$ of DNA (2.5 $\mathrm{ng} / \mu \mathrm{L})$. Primer combinations

153 and cycle conditions are described in Table 1. At the end of each qPCR run, a 154 melting curve analysis was performed from 60 to $99^{\circ} \mathrm{C}$ with an increase of $0.5^{\circ} \mathrm{C}$ 155 every $10 \mathrm{~s}$. Purity of the qPCR products was checked by the observation of a single 156 peak on the melting curve, while correct size of the amplicons was confirmed on a $1571 \%(\mathrm{w} / \mathrm{v})$ agarose gel. For each qPCR reaction, a standard curve comprising serial 158 10-fold dilutions of the target gene was created. Standards were obtained by 159 amplifying the target genes from the following sources: Escherichia coli (16S rRNA 160 gene) and Aspergillus niger (18S rRNA gene). 
161 Fungal community analysis by T-RFLP

162 Terminal restriction fragment length polymorphism (T-RFLP) was used to determine

163 whether the fungal community of a soil sample differed among the three successive 164 DNA extractions performed. Internal transcribed spacer (ITS) regions were used to 165 target fugal community by amplifying ITS1 region, 5.8S rRNA gene and ITS2 region 166 using specific primers (Table 1). A single replicate from each soil sample was 167 randomly chosen to determine the fungal community by T-RFLP. Three PCR 168 reactions were performed for each sample. PCR was performed with final reaction 169 volume of $25 \mu \mathrm{L}$, which contained $2.5 \mu \mathrm{L}$ of $10 \mathrm{X}$ PCR reaction buffer with $20 \mathrm{mM}$ of $170 \mathrm{MgCl}_{2}$ (Roche Applied Sciences, Indianapolis, IN, USA), $200 \mu \mathrm{M}$ of dNTPs, $1 \mu \mathrm{M}$ of 171 each primer, $1.25 \mathrm{U}$ of Fast Start DNA polymerase (Roche Applied Sciences) and 5 $172 \mu \mathrm{L}$ of template DNA $(5 \mathrm{ng} / \mu \mathrm{L})$. Cycle conditions are given in Table 1 . The forward 173 primer was labelled with the fluorescent dye 6-FAM, while the reverse primer was 174 labelled with NED (Applied Biosystems, Foster City, CA, USA). Successful 175 amplification was confirmed by running PCR products on a 1.5\% (w/v) agarose gel. 176 PCR products were digested with 10 units of Hhal (Thermo Scientific) at $37^{\circ} \mathrm{C}$ for 3

177 h. Enzyme inactivation was performed by incubation at $80{ }^{\circ} \mathrm{C}$ for $20 \mathrm{~min}$. After 178 inactivation, digested PCR products were purified using ethanol precipitation. 179 Appropriate dilutions, based on test runs of terminal restriction fragments (TRFs), 180 were analysed with an ABI 3130 sequencer using GeneScan ${ }^{\mathrm{TM}}$ - 500 LIZ (Applied 181 Biosystems) as a size standard.

\section{Prokaryotic and fungal community analyses by 454-pyrosequencing}

183 Prokaryotic and fungal community composition, as well as diversity were investigated 184 by $454-$ pyrosequencing (454 Life Sciences, Roche). The prokaryotic community 185 (bacterial and archaeal communities) was targeted by amplification of V3 and V4 186 regions of the 16S rRNA gene, while the fungal community was assessed by 187 amplification of V7 and V8 regions of the 18S rRNA gene. Amplicons were generated 188 by PCR reactions of $50 \mu \mathrm{L}$ (total volume) containing $5 \mu \mathrm{L}$ of $10 \mathrm{X}$ PCR reaction buffer 189 with $20 \mathrm{mM}$ of $\mathrm{MgCl}_{2}$ (Roche Applied Sciences), $200 \mu \mathrm{M}$ of dNTPs, $1 \mu \mathrm{M}$ of each 190 primer, $1.25 \mathrm{U}$ of Fast Start DNA polymerase (Roche Applied Sciences) and $5 \mu \mathrm{L}$ of 191 template DNA (5 $\mathrm{ng} / \mu \mathrm{L})$. PCR reactions were performed in duplicate, which were 192 mixed prior to purification. As for T-RFLP, only a single replicate of each sample was 193 used (same replicate as used for T-RFLP). Primer sequences and cycle conditions 194 are shown in Table 1. Confirmation of amplification was performed by 195 electrophoresis of PCR products on a $1.5 \%(\mathrm{w} / \mathrm{v})$ agarose gel. PCR products were 
196 purified using the GeneJET PCR Purification Kit (Thermo Scientific), and quantified 197 using a Qubit 2.0 Fluorometer (Life Technologies). Purified and quantified PCR 198 products were then mixed in equimolar amounts at a final concentration of 500 $199 \mathrm{ng} / \mu \mathrm{L}$. The equimolar mixture was purified by electrophoresis of pooled amplicons in 200 a $1.5 \%(\mathrm{w} / \mathrm{v})$ agarose gel and excision of the band. DNA was recovered from 201 agarose using the GeneJET Gel Extraction Kit (Thermo Scientific). Gel purified 202 amplicons were sequenced using an FLX genome sequencer in combination with 203 titanium chemistry (Macrogen Inc., Seoul, South Korea).

\section{Data analysis}

205 Differences in DNA yield, bacterial and fungal abundances, represented as 206 percentage of recovery after first, second and third extraction, were analysed by two207 way ANOVA using IBM SPSS Statistics for Macintosh software, version 23 (IBM 208 Corp., Armonk, NY, USA). Similarly, a two-way ANOVA was used to analyse 209 differences in total DNA yield as well as bacterial and fungal abundances observed 210 after all three successive extractions. T-RFLP analyses were performed according to 211 (Mendes et al., 2012). Briefly, profiles were analysed using PeakScanner v1.0 212 software (Applied Biosystems), and TRFs of less than $50 \mathrm{bp}$ and bigger than $800 \mathrm{bp}$ 213 were excluded. The relative abundance of a single TRF was calculated as percent 214 fluorescence intensity relative to total fluorescence intensity of the peaks (Culman et 215 al., 2008). An average of three replicates was calculated for each individual sample. 216 Principal Component Analysis (PCA) was used to assess differences in fungal 217 community composition between successive DNA extractions of a single sample, 218 within a single DNA extraction kit. Multivariate statistical analysis was performed 219 using Canoco 4.5 software (ter Braak and Šmilauer, 2002).

220 Sequencing analyses were performed using a Snakemake workflow (Koster and 221 Rahmann, 2012), which follows a standard operating procedure for 454 data in 222 mothur version 1.33.2 (Schloss et al., 2009). Flowgrams were demultiplexed allowing 223 two mismatches on the barcodes and three mismatches on the forward primer, 224 flowgrams were trimmed to a size of 635 flows. Flowgrams were corrected using the 225 shhh.flows command, which is a mothur implementation of the original PyroNoise 226 algorithm (Quince et al., 2011). Afterwards, results of the different sff files were 227 combined for further analysis. Merged sequences were aligned and classified with 228 SINA (Pruesse et al., 2012) against the SILVA 115 database (Quast et al., 2013). 229 After alignment, some reads did not align to the same region as most of the reads. 230 Therefore, reads were kept if containing at least $90 \%$ of its sequence aligned to a 
231 region common to all reads. To reduce sequence errors, sequences that were within

232 two mismatches of each other were merged. Chimeric sequences were identified and

233 removed using UCHIME (Edgar et al., 2011). Operational taxonomic Units (OTUs)

234 were formed at maximum distance of 0.03 using the dist.seqs command and average

235 neighbor clustering. For each OTU a consensus taxonomy was determined using the

236 classify.otu command. Representative sequences for each OTU were re-aligned to

237 the SILVA reference alignment, and a neighbor joining tree was created using the

238 clearcut program (Sheneman et al., 2006). Taxonomic classification and OTU

239 clustering data were combined into the BIOM format (McDonald et al., 2012) for

240 further downstream analyses with the Phyloseq (McMurdie and Holmes, 2013)

241 package for $\mathrm{R}$ (R-Core Team, 2014). Due to a low quality sequencing output, E2

242 performed with FS on sample sandy 3 was removed from the fungal dataset after

243 sequence quality control. Numbers of reads were not rarefied among samples

244 (normalized to the lowest number of reads) before clustering analysis, since recent

245 work has shown that rarefying is unnecessary (McMurdie and Holmes, 2014).

246 Instead, OTU raw abundances were transformed to relative abundances prior

247 analysis, which has been shown to be an alternative to rarefying (McMurdie and

248 Holmes, 2014). Prior to clustering analysis, sample-wise singletons and doubletons

249 were discarded, where an OTU would be kept only if observed in at least one sample

250 and contained at least three reads.

251 Diversity analyses were performed using OTU tables that had been rarefied to the 252 lowest number of reads and included singletons and doubletons. The lowest number 253 of reads for the 16S rRNA dataset was 3180, whereas for the 18S rRNA dataset it 254 was 3440. An additional filtering step was done only for the 18S rRNA gene dataset, 255 where only reads belonging to the kingdom Fungi were kept for downstream 256 analyses. Raw sequencing data obtained from 454-pyrosequencing were submitted 257 to the NCBI Sequence Read Archive (SRA) under the accession numbers 258 SRR5040745 (16S rRNA reads) and SRR5043664 (18S rRNA reads). For all 259 statistical tests performed, statistical significance was accepted at $p<0.05$. 


\section{Manuscript to be reviewed}

260 Results

261 DNA yield

262 Overall, DNA extraction with both commercial kits yielded a substantial amount of

263 DNA, regardless of soil type. Efficiency was higher when using the FS than the PS

264 DNA extraction kit, independent of soil type. FS yielded around four times more DNA 265 from clay soils and around three times more DNA from sandy soils than PS (Figure 266 2, Table S2). For almost all soil samples, DNA extractions performed with both kits 267 yielded the highest DNA concentration in E1, except for clay 2 (PS extraction) and 268 sandy 3 (extraction performed with both kits), which showed the highest DNA yield in 269 E2 (Table S2). DNA extraction of clay 1 was similar for both kits, where the highest 270 amount of DNA was extracted in E1 (around $60 \%$ of total DNA obtained), with E2 271 and E3 showing lower DNA concentration compared to previous extractions (Figure $2722 \mathrm{~A}, 2 \mathrm{C}$ and Table S2A). Less than half of the total DNA obtained from clay 2 was 273 extracted in E1 for both kits, with E2 and E3 still yielding substantial amounts of DNA 274 (Figure 2A, 2C and Table S2A). Clay 3 showed distinct DNA extraction patterns 275 when comparing both kits (Figure $2 A$ and $2 C$ ). Using PS, around 95\% of total DNA 276 extracted was recovered in E1 (Figure 2A). However, when using FS, only $40 \%$ of 277 the total DNA extracted was recovered in E1 (Figure 2C). Among clay soils, 278 regardless of the kit used, clay 3 yielded the highest total DNA concentration 279 followed by clay 1 and clay 2 . The same trend was also observed for sandy soils, 280 where sandy 1 , a pasture soil as clay 3 , yielded the highest total DNA concentration, 281 followed by sandy 3 and sandy 2 (Figure 2B, 2D and Table S2B). DNA extractions of 282 sandy 1 showed a similar pattern regardless the kit used, with 55-60\% of DNA 283 obtained in E1 (Figure 2B, 2D and Table S2B). The same was observed for sandy 2, 284 with approximately $55 \%$ of the total DNA recovered being extracted in E1 (Figure 2B, $2852 \mathrm{D}$ and Table S2B). Comparing all three successive extractions, sandy 3 showed the 286 highest DNA concentration in E2, for both kits (Figure 2B, 2D and Table S2B). 287 Approximately $50 \%$ of the total DNA extracted was obtained in E2, with $\mathrm{E} 1$ yielding 288 more DNA than E3. Different soil management influenced the total amount of DNA 289 obtained, regardless of DNA extraction methodology. Pasture soil yielded a 290 considerably higher amount of total DNA compared to other managements, with pine 291 forest soil showing the least amount of DNA. DNA extraction kit had a significant 292 effect on the total DNA yield, with FS extracting significantly more DNA than PS ( $p<$ 293 0.05), however, soil type did not significantly influence DNA yield $(p>0.05)$. No 294 significant interaction was observed between DNA extraction kit and soil type $(p>$ 
295 0.05). Neither soil type nor DNA extraction kit had a significant effect on DNA yield in

296 E1, E2 and E3 (recovery percentage) $(p>0.05)$.

\section{Bacterial and fungal abundances in successive DNA extractions}

298 Overall, qPCR results of both targeted genes (16S and 18S rRNA) indicated similar 299 patterns as observed in DNA quantification of all soil samples (Figures 2, 3 and 4). 300 Bacterial and fungal abundances in clay 1 decreased with successive extractions, for 301 both DNA kits, where no substantial increase in cumulative abundance could be 302 seen after E2 (Figures 3A, 3C, 4A and 4C). Interestingly, clay 2 presented almost 303 constant bacterial and fungal abundances in all three DNA extractions, which 304 resulted in a linear cumulative abundance increase with successive extractions for 305 both kits (Figures 3A, 3C, 4A and 4C). Differently from the other clay soils, clay 3 306 showed contrasting results when comparing DNA extraction kits. When using PS, 307 bacterial and fungal abundances in E2 and E3 were very low compared to E1, 308 indicating that almost all bacterial and fungal DNA available had been already 309 extracted in E1 (Figures $3 \mathrm{~A}$ and 4A). However, when using FS, bacterial and fungal 310 abundances as measured in E2 and E3 were considerably higher compared to E1 311 (Figures $3 \mathrm{C}$ and $4 \mathrm{C}$ ), indicating that substantial amounts of bacterial and fungal DNA 312 were still present in the soil sample after E1. As observed for total DNA yield, 313 bacterial and fungal abundances in clay soils were higher in samples extracted with 314 FS compared to PS. This was not observed for sandy soils, where bacterial and 315 fungal abundances were always higher in soil samples that had DNA extracted with 316 PS. Irrespective of the kit used, bacterial and fungal abundances in sandy 1 samples 317 were highest in E1 (Figures 3B, 3D, 4B and 4D). However, when using PS, around 318 only half of total bacterial and fungal DNA was recovered in E1, whereas, when using 319 FS, these values were around $80 \%$. A very distinct pattern was observed for bacterial 320 and fungal abundances in sandy 2, when comparing DNA extraction kits. Samples 321 extracted with PS had a recovery of around $45 \%$ of total bacterial and fungal DNA in 322 E1, whereas samples extracted with PS showed a recovery of more than $80 \%$ of 323 total bacteria and fungi abundance in E3 (Figures 3B, 3D, 4B and 4D). After all three 324 successive extractions, cumulative bacterial and fungal abundances were five times 325 higher in samples extracted with PS compared to those extracted with FS, even with 326 DNA yield being higher in samples extracted with FS. The total number of bacterial 327 16S rRNA gene copies in sandy 3 was similar for both kits (Figure 3B and 3D). The 328 same was observed for total fungal abundance. Total bacterial and fungal 329 abundances were slightly higher in samples extracted with PS, however, samples 330 extracted with either kit presented higher fungal abundance in E2 and E3 compared 
331 to $\mathrm{E} 1$ (Figure $4 \mathrm{~B}$ and $4 \mathrm{D}$ ), which was not noticed for bacterial abundance. As

332 observed for sandy 1 and sandy 2, a higher total DNA yield in samples of sandy 3,

333 which had been extracted with FS, did not result in higher bacterial and fungal

334 abundances. Such contrasting result was particular of sandy soils, since clay soils

335 with higher DNA yield presented higher bacterial and fungal abundances. Different

336 DNA extractions kits did not affect significantly bacterial nor fungal abundance in clay

337 and sandy soils $(p>0.05)$. However, bacterial abundance was significantly affected

338 by soil type $(p<0.05)$.

339 The use of different commercial kits for DNA extraction did neither affect bacterial nor

340 fungal abundance (percentage of recovery) observed after first, second and third

341 extractions $(p>0.05)$. Soil type, however, had a significant effect on the total

342 bacterial abundance $(p<0.05)$ and fungal abundance $(p<0.05)$ only after the first

343 and third extraction.

\section{Fungal community analysis by T-RFLP}

345 Fungal community composition was initially measured by T-RFLP analysis, and PCA 346 analysis was used to assess differences among different extractions of a single 347 sample, within a single DNA extraction kit and soil type. Since forward and reverse 348 primers were labelled, both were analysed to investigate whether results were 349 consistent independently of primer use. Analyses of both primers showed similar 350 results for both DNA extraction kits and both soil types (Figure S3 and S4). Fungal 351 communities detected in clay soils showed to be distinct among different land 352 management types, regardless of the DNA extraction kit used (Figure S3). Overall, 353 successive DNA extractions yielded different fungal communities in all clay soils.

354 With the use of PS, clay 1 and clay 2 showed clearly different fungal communities 355 when comparing the three extractions. However, for clay 3 fungal community 356 composition present in E1 was different from E2 and E3, which were similar to each 357 other (Figure S3A and S3B). Results obtained with FS were slightly different from 358 PS. Clay 1 presented a different fungal community in each successive DNA 359 extraction. However, clay 2 showed a similar fungal community present in E1 and 360 E2, which was different from the community observed in E3. Fungal communities 361 detected for clay 3 were similar for all three extractions (Figure S3C and S3D). As 362 observed for clay soils, fungal communities observed in sandy soils were also distinct 363 among different land management, independently of the DNA extraction kit used 364 (Figure S4). However, differently from clay soils, successive DNA extractions of 365 sandy soils yielded similar fungal communities, especially when using PS (Figure 
366 S4A and S4B). Total DNA extraction with PS revealed a very different fungal

367 community when comparing different sandy soils, but not within soils. Successive

368 DNA extraction with FS revealed a different fungal community only for sandy soils 1

369 and 2, with sandy 1 showing a similar community on the first two extractions,

370 whereas sandy 2 presented a different community in all three extractions (Figure

371 S4C and S4D).

372 Prokaryotic and Fungal community analysis by 454-pyrosequencing

373 To investigate further whether successive DNA extractions of the same soil sample 374 yield different prokaryotic and fungal communities, as well as to confirm T-RFLP 375 results (fungal community), next-generation sequencing was performed on all three 376 extractions obtained from each soil. The Chao1 index was used to measure species 377 richness, whereas community diversity was described by Shannon index. Overall, 378 apparent prokaryotic species richness in clay soils increased in E2 or E3 (Figure 5A), 379 with clay 1 and clay 3 (PS) being the only two samples that showed a decrease in 380 species richness with successive extractions. Observed prokaryotic community 381 diversity decreased with successive DNA extractions (Figure 5A), regardless of the 382 DNA extraction kit used. However, for clay 1 (PS) and clay 2 (FS) diversity increased 383 in E3, compared to the previous extraction. Observed fungal species richness varied 384 considerably across clay soils and DNA extraction kit (Figure 6A). From all samples 385 extracted with FS, clay 2 was the only sample that did not have its highest species 386 richness value in E1. The same trend was observed for samples extracted with PS, 387 where the highest species richness value was observed in E1. Observed fungal 388 community diversity either increased or remained the same with successive 389 extractions (Figure 6A), regardless of the extraction kit used. Clay 1 (FS) was the 390 only sample, within clay soils, that presented a decrease in fungal diversity with 391 successive DNA extractions (Figure 6A). Overall, observed prokaryotic species 392 richness in sandy soils decreased with successive extractions, with sandy 1 (PS and 393 FS) being the only sandy soil where species richness was highest not in E1 (Figure 394 5B). Similar to clay soils, observed prokaryotic diversity in sandy soils decreased with 395 successive extractions (Figure 5B). Sandy 3 (PS) was the only exception, where the 396 highest diversity was observed in E2. The highest observed fungal species richness 397 value in most of the sandy soil samples was obtained only in E2 or E3 (Figure 6B). 398 Sandy 1 (FS) and sandy 2 (PS) were exceptions and had their highest species 399 richness value in E1. Observed fungal diversity in sandy soils was similar to clay 400 soils, where diversity increased with successive DNA extractions (Figure 6B). The 
401 only exception was sandy 1 (FS), which showed a decrease in observed diversity 402 with successive extractions (Figure 6B).

403 Multidimensional scaling analysis (MDS), using unweighted and weighted Unifrac 404 distances (Hamady et al., 2010), were used to compare prokaryotic and fungal 405 community composition in successive DNA extractions in both soil types. Detected 406 prokaryotic community composition in clay soils showed to be similar in all three 407 successive DNA extractions, regardless of the extraction kit used (Figure 7A and 408 S5A). When weighted Unifrac distance was used, clay 1 (PS) was the soil sample 409 that presented the most different prokaryotic community among successive DNA 410 extractions, with E1 and E3 being more similar to each other. However, when 411 unweighted Unifrac distance was used, clay 3 (PS) showed to have the most 412 different prokaryotic community among successive DNA extractions (Figure S5A). 413 Despite successive DNA extractions yielding similar prokaryotic community 414 composition, some taxa clearly increased in relative abundance when multiple 415 extractions were performed in a single sample. For instance, a clear increase in 416 relative abundance of the taxa Thaumarchaeota and Firmicutes could be seen with 417 successive DNA extractions in all clay soil samples (Table S3). Other taxa, such as 418 Verrucomicrobia, Choroflexi and Acidobacteria, showed considerably higher relative 419 abundance in E2 and/or E3 for some of the soil samples (Figure 8A). Differently from 420 prokaryotic communities, observed fungal communities in clay soils were different in 421 successive DNA extractions (Figure 9A and S6A). As observed for bacterial and 422 archaeal communities, clay 1 showed the biggest variation in fungal community when 423 comparing successive extractions. Successive extractions promoted an increase in 424 relative abundance of a few fungal taxa in some of the clay soils (Figure 10A), 425 however, such increase showed to be kit dependent in most of the cases. Sandy 426 soils, as clay soils, presented a similar prokaryotic community composition when 427 successive extractions were compared (Figure 7B and S5B). Of all three sandy soils, 428 sandy 3 presented the biggest difference in prokaryotic community composition when 429 comparing successive extractions. As observed for clay soils, some taxa were 430 enriched when multiple extractions were performed in a single soil sample. 431 Firmicutes and Planctomycetes increased in relative abundance with successive 432 DNA extractions in all sandy soils (Figure 8B and Table S3). Despite not having an 433 increase in relative abundance in all soil samples, some taxa showed a considerable 434 increase with successive DNA extraction, such as Actinobacteria, Chloroflexi and 435 Proteobacteria (Figure 8B). Fungal community composition in successive DNA 436 extractions on sandy soils was rather similar, contrary to clay soils (Figure 9B and 
437 S6B). However, for sandy 1 fungal community in E2 showed to be different than

438 community present in E1 and E3, when analysis was performed using unweighted

439 Unifrac distance (Figure S6B). Increase in relative abundance of fungal taxa with

440 successive extraction in sandy soils was also observed, with taxa Ascomycota

441 presenting an increase in all sandy soil samples, regardless the DNA extraction kit

442 used (Figure 10B). A few bacterial and fungal taxa (phylum level) were observed only

443 in E2 and/or E3, indicating that additional taxonomical groups can be identified with

444 successive DNA extractions. However, the relative abundances of such taxa were

445 always very low (lower than $0.05 \%$ for prokaryotes and $0.02 \%$ for fungi), and the

446 occurrence of additional taxa was not observed for all soil samples (Table S4).

447 Analysis of similarity (ANOSIM) was used to compare microbial communities in both

448 soils, which had been obtained by different DNA extraction strategies. Prokaryotic

449 community composition, in both soils, was not influenced by DNA extraction kit ( $p>$

450 0.05). Fungal community composition, obtained with different DNA extraction kits,

451 was significantly different only in clay soils (ANOSIM, $p<0.05, R=0.210$ ). 


\section{Discussion}

\section{Manuscript to be reviewed}

453 Currently, characterization of complex microbial communities such as those present

454 in soil relies heavily on the use of molecular approaches. Such approaches are often 455 used to assess microbial abundance, community composition and diversity. 456 Independently of the approach used, DNA contained in a soil sample needs to be 457 separated from the soil phase as a first step. Therefore, soil DNA extraction is a 458 crucial step, and success of downstream processes used to characterize soil 459 microbial communities will depend largely on how well this first step was performed. 460 Previous studies have shown that not all microbial DNA contained in a soil sample is 461 extracted with a single DNA extraction (Burgmann et al., 2001; Feinstein et al., 2009; 462 Jones et al., 2011). Here, we performed multiple successive DNA extractions on a 463 number of representative soil samples to assess bias related to incomplete DNA 464 extractions, using two widely used commercial soil DNA extraction kits. Moreover, 465 different molecular techniques were applied to determine whether successive DNA 466 extractions would lead to different apparent microbial communities.

467 DNA yield of all used soils was affected by successive DNA extractions. Only one out 468 of twelve soils tested, clay 3 (PS), had more than $90 \%$ of all extracted DNA 469 recovered after $\mathrm{E} 1$. All other soil samples showed recovery from $30 \%$ to $60 \%$, of the 470 total obtained DNA, in E1, which indicates that a significant portion of extractable soil 471 DNA is left behind at the end of the first extraction. This supports results previously 472 described in the literature (Feinstein et al., 2009; Jones et al., 2011). Previous work 473 has shown that DNA yield decreased with successive DNA extraction when, after the 474 first extraction, the soil pellet was washed with extraction buffer; which indicates that 475 DNA obtained in the successive extractions would probably come from newly lysed 476 cells (Feinstein et al., 2009). Soil samples were frozen between the E2 and E3, as 477 extractions were continued the following day. Effects of freezing-thawing on cell lysis, 478 which would consequently affect DNA yield, cannot be excluded. However, it is 479 expected the size of this effect not to exceed that of the bead-beating procedure 480 used prior and after freezing. Overall, DNA yield was significantly higher using FS 481 compared to PS, around four times for clay soils and three times for sandy soils. This 482 is in line with previous studies that have also shown that FS is more efficient than PS 483 in extracting DNA from various soil types (Leite et al., 2014; Vishnivetskaya et al., 484 2014). Considering that the initial cell lysis step, when using $P S$, is much more 485 extensive compared to FS $\left(5.5 \mathrm{~m} \mathrm{~s}^{-1}\right.$ for $10 \mathrm{~min}$ for PS and $6.0 \mathrm{~m} \mathrm{~s}^{-1}$ for $40 \mathrm{sec}$ for 486 FS), this might be surprising at first sight, however, after cell lysis, released DNA will 487 strongly interact with soil particles, which can influence DNA yield (Lombard et al., 
488 2011). Romanowski et al. (1993) demonstrated that up to $80 \%$ of added DNA was

489 found to be adsorbed to sediment in less than $20 \mathrm{~min}$. DNA adsorption to soil 490 particles may be increased by DNA shearing (Pietramellara et al., 2001), however, 491 DNA fragmentation of both kits was very similar (Figure S7). Therefore, reasons for a 492 higher DNA yield when using FS may be that this kit promotes not only a better soil 493 homogenization, improving disruption of soil aggregates, but also a better cell lysis 494 and DNA desorption from soil components. Furthermore, FS may have a decreased 495 DNA degradation compared to PS, once DNA is released from cells. Perhaps, a very 496 extensive cell lysis step, as used for PS, is counterproductive, as it would allow for 497 adsorption of DNA to soil particles for a longer period. Vishnivetskaya et al. (2014) 498 showed that FS was more efficient than PS in genomic DNA recovery from a 499 permafrost soil, which could also be attributed to higher bacterial cell lysis efficiency. 500 Differences in bead to soil ratio has also been found to influence DNA yield while 501 bead-beating is used for mechanical cell lysis (Burgmann et al., 2001). However, 502 DNA extraction kits did not significantly affect DNA yield when recovery percentage 503 was taken into account, which shows that independently of the kit and bead-beating 504 time, more soil DNA was consistently obtained with successive extractions.

505 Similarly to the DNA yield, cumulative bacterial and fungal abundances increased 506 with successive extractions in all samples, confirming that microbial DNA present in a 507 soil sample is not fully recovered with a single extraction. Similar results have been 508 reported earlier, where for most of the soils analysed bacterial and fungal 509 abundances levelled off after three successive extractions (Feinstein et al., 2009). 510 Jones et al. (2011) also found that bacterial abundance increased considerably when 511 multiple DNA extractions were performed on the same soil sample. In the present 512 study, however, there was a considerable discrepancy between results of DNA yield 513 and observed abundances of bacteria and fungi. Although DNA extraction kit 514 significantly influenced total DNA yield, it did not influence observed total bacterial 515 and fungal abundances. Although not significant, bacterial and fungal abundances 516 were always higher on clay soil samples extracted with FS, however, differences 517 were much smaller than those observed for DNA yield, especially for clay 2 . That 518 may indicate that using FS more DNA of non-microbial origin could be extracted, or 519 that not all microbial DNA extracted is amplified during QPCR, which could be due to 520 specificity or purity issues. Bacterial abundance in a permafrost soil showed to be 521 around four times higher in samples extracted with FS compared to PS 522 (Vishnivetskaya et al., 2014). The opposite was observed for sandy soil, where 523 bacterial and fungal abundances were always higher on samples extracted with PS, 
524 despite DNA yield being higher in samples extracted with FS. Lower microbial

525 abundances in samples extracted with FS may be attributed to a lower DNA purity

526 obtained when using this kit, which could inhibit enzymatic reactions (Wilson, 1997).

527 Both 260/280 and 260/230 ratios, which indicate DNA purity, were consistently lower

528 in sandy soil samples that were extracted with FS (Table S5). Differently from what

529 was reported by Kuramae et al. (2012), pasture and arable soil samples presented

530 higher microbial abundance compared to forest soils.

531 Fungal communities in successive DNA extractions, which were identified by T-RFLP

532 analysis, varied greatly in clay soils, whereas in sandy soils, fungal communities

533 were more similar to each other, especially for samples extracted with PS.

534 Differences observed between soil types indicate that clay soils might promote a

535 greater degree of protection to fungal cells, which could make cell lysis more difficult.

536 These results differ from previous findings described on the literature, where fungal

537 communities in successive DNA extractions of three different soil types (organic, clay

538 and sand) were almost identical (Feinstein et al., 2009). Soils used by Feinstein et al.

539 (2009) had a similar sand and clay content to those used here, therefore, other soil

540 properties may play a role. Furthermore, soils analysed here may have a higher

541 abundance of fungal spores, which could explain the differences observed among

542 successive DNA extractions.

543 Ecological diversity measures, such as the Chao1 and Shannon indices, were used

544 in order to determine whether apparent prokaryotic and fungal richness and diversity

545 would change in successive DNA extractions. Chao1 is often used to estimate

546 species richness (total number of species in a community), and it relies on the

547 presence of singletons and doubletons, therefore, giving more weight to rare

548 individuals (Hill et al., 2003). The Shannon index on the other hand takes into

549 consideration not only the number of species in a community but also their relative

550 abundance, but also giving more weight to rare than common species (Hill et al.,

551 2003). For both variables, soil type and extraction kit, increase of prokaryotic and/or

552 fungal species richness with successive DNA extraction was observed. This

553 suggests that more taxa/OTUs are obtained when successive DNA extractions are

554 performed, therefore, presenting a more realistic picture of the microbial community

555 in those samples. Those taxa/OTUs possibly represent also rare organisms, which

556 can be present in low abundance in the soil for various reasons, including dormancy.

557 It is known that dormancy is a common life history strategy in microbes (Jones and

558 Lennon, 2010), and it might as well be that metabolic changes caused by such

559 strategy, even in nonsporulating species, lead to changes in cell structure and 
560 morphology that make cells harder to lyse. Increase in diversity with successive DNA

561 extractions was also observed, especially in fungal communities. Increase in

562 Shannon index (diversity) indicated that with successive extractions, not only new

563 taxa/OTUs were being observed, but also that taxa/OTUs observed in these

564 successive extractions appeared at more similar relative abundances. Therefore,

565 results from both diversity indexes suggest that extracting soil DNA only once does

566 not give a realistic description of species richness and diversity.

567 To determine whether successive DNA extractions would yield different prokaryotic

568 and fungal communities in clay and sandy soils, cluster analyses of the $16 \mathrm{~S}$ and $18 \mathrm{~S}$

569 rRNA gene sequencing data were performed. MDS plots revealed that prokaryotic

570 communities obtained in E2 and E3 were similar to E1, for both soils. At phylum

571 level, differences that were observed among successive DNA extractions, of the

572 same soil sample, were in majority shifts in abundance, as observed before

573 (Feinstein et al., 2009; Jones et al., 2011). Various phyla increased in relative

574 abundance with successive DNA extractions, such as Thaumarchaeota and

575 Firmicutes in all clay soils and Firmicutes and Planctomycetes in all sandy soils.

576 Such increase in relative abundance may indicate that organisms belonging to these

577 phyla are more difficult to lyse, which could be a consequence of their life strategy

578 and/or morphological characteristics, such as sporulation. However, Feinstein et al.

579 (2009) found that Firmicutes, gram-positive bacteria that are well known for having

580 the ability to form endospores, did not increase in relative abundance with

581 successive DNA extractions in clay and sandy soils. It is important to mention that

582 only the first and the sixth DNA extractions were sequenced in their study. As

583 observed by Feinstein et al. (2009), bacterial phyla that were not identified in E1, but

584 identified in E2 and/or E3 were always in a very low relative abundance. Differently

585 from prokaryotic community, cluster analyses of the 18S rRNA gene data retrieved

586 from successive DNA extractions revealed that communities obtained in E1 were

587 different from E2 and E3 only in clay soils. Such difference was seen when analyses

588 were performed with both, unweighted and weighted Unifrac distances, which

589 confirms that not all fungal taxa were recovered after a single extraction. The

590 opposite has been reported in literature, where fungal communities analysed by T-

591 RFLP from six successive DNA extractions were very similar to each other (Feinstein

592 et al., 2009). A low number of fungal taxa were identified only in E2 and/or E3, with

593 the majority being unknown taxa, which may indicate that incomplete DNA

594 extractions could prevent the identification of new fungal taxa. As for prokaryotic

595 communities, major shifts in community composition were due to changes in relative 
596 abundance of fungal taxa. The use of both markers, 18S rRNA gene and ITS

597 regions, showed similar results, however, the dissimilarity of fungal communities

598 analysed by T-RFLP was higher for a few soil samples. A possible reason for that is

599 the higher variability of the ITS regions compared to the 18S rRNA gene, which allow

600 for a better taxonomic differentiation (Anderson and Cairney, 2004).

601 In conclusion, successive rounds of DNA extraction from several representative soil 602 samples, using two widely commercial DNA extraction kits, resulted in the 603 identification of additional prokaryotic or fungal phyla in some of the analysed soils. 604 However, when identified, additional phyla were always present at very low relative 605 abundance. Additionally, shifts in relative abundance of well-known groups of soil 606 archaea, bacteria and fungi were observed. In some cases, changes in relative 607 abundance were such that communities originating from the same soil sample, but 608 from a different extraction, were seen as different communities, as indicated by MDS 609 plots. Total bacterial and fungal abundance increased considerably with successive 610 DNA extractions, confirming that not all soil DNA is extracted in a single extraction.

611 Often, in microbiome studies, multiple parallel extractions of a sample are performed, 612 and DNA originating from all extractions is pooled for further experiments. Such 613 strategy attempts to reduce variability between extractions in order to provide a more 614 realistic representation of the microbiome of that particular sample. However, such 615 strategy would still fail to provide an accurate estimation of the relative abundance of 616 microbial groups present in that particular microbiome. Therefore, as Feinstein et al. 617 (2009), we argue that in order to improve microbial characterization, leading to a 618 more comprehensive microbiome analysis, DNA should be obtained from multiple 619 successive extractions of the same soil sample. DNA obtained from multiple 620 successive extraction should be pooled previously being used in further experiments.

621 Such approach may reduce DNA extraction bias and provide a better overall picture 622 of the soil microbial community under analysis. 


\section{Acknowledgements}

624 We thank Henk Martens and Lucas William Mendes for the assistance with the T625 RFLP experiments and analysis. Publication number XXXX from the Netherlands 626 Institute of Ecology (NIOO-KNAW). 


\section{Manuscript to be reviewed}

\section{References}

628 Anderson, I.C., Cairney, J.W.G., 2004. Diversity and ecology of soil fungal 629 communities: increased understanding through the application of molecular 630 techniques. Environ Microbiol 6, 769-779.

631

632

633

634

635

636

637

638

639

640

641

642

643

644

645

646

647

648

649

650

651

652

653

654

655

656

657

658

659

660

661

662

663

664

665

666

667

668

669

670

671

672

673

674

675

676

677

Bardgett, R.D., van der Putten, W.H., 2014. Belowground biodiversity and ecosystem functioning. Nature 515, 505-511.

Bates, S.T., Berg-Lyons, D., Caporaso, J.G., Walters, W.A., Knight, R., Fierer, N., 2011. Examining the global distribution of dominant archaeal populations in soil. Isme J 5, 908-917.

Bender, S.F., Plantenga, F., Neftel, A., Jocher, M., Oberholzer, H.R., Kohl, L., Giles, M., Daniell, T.J., van der Heijden, M.G.A., 2014. Symbiotic relationships between soil fungi and plants reduce N2O emissions from soil. Isme J 8, 1336-1345.

Berry, A.E., Chiocchini, C., Selby, T., Sosio, M., Wellington, E.M.H., 2003. Isolation of high molecular weight DNA from soil for cloning into BAC vectors. FEMS microbiology letters $223,15-20$.

Braid, M.D., Daniels, L.M., Kitts, C.L., 2003. Removal of PCR inhibitors from soil DNA by chemical flocculation. J Microbiol Methods 52, 389-393.

Burgmann, H., Pesaro, M., Widmer, F., Zeyer, J., 2001. A strategy for optimizing quality and quantity of DNA extracted from soil. J Microbiol Methods 45, 7-20.

Culman, S.W., Gauch, H.G., Blackwood, C.B., Thies, J.E., 2008. Analysis of T-RFLP data using analysis of variance and ordination methods: A comparative study. $J$ Microbiol Meth 75, 55-63.

Delmont, T.O., Prestat, E., Keegan, K.P., Faubladier, M., Robe, P., Clark, I.M., Pelletier, E., Hirsch, P.R., Meyer, F., Gilbert, J.A., Le Paslier, D., Simonet, P., Vogel, T.M., 2012. Structure, fluctuation and magnitude of a natural grassland soil metagenome. Isme J 6, 1677-1687.

Delmont, T.O., Robe, P., Cecillon, S., Clark, I.M., Constancias, F., Simonet, P., Hirsch, P.R., Vogel, T.M., 2011. Accessing the soil metagenome for studies of microbial diversity. Appl Environ Microbiol 77, 1315-1324.

Dong, D.X., Yan, A., Liu, H.M., Zhang, X.H., Xu, Y.Q., 2006. Removal of humic substances from soil DNA using aluminium sulfate. J Microbiol Meth 66, 217-222.

Edgar, R.C., Haas, B.J., Clemente, J.C., Quince, C., Knight, R., 2011. UCHIME improves sensitivity and speed of chimera detection. Bioinformatics 27, 2194-2200.

Falkowski, P.G., Fenchel, T., Delong, E.F., 2008. The microbial engines that drive Earth's biogeochemical cycles. Science 320, 1034-1039.

Feinstein, L.M., Sul, W.J., Blackwood, C.B., 2009. Assessment of Bias Associated with Incomplete Extraction of Microbial DNA from Soil. Appl Environ Microb 75, 54285433. 
679 Frostegard, A., Courtois, S., Ramisse, V., Clerc, S., Bernillon, D., Le Gall, F., 680 Jeannin, P., Nesme, X., Simonet, P., 1999. Quantification of bias related to the 681 extraction of DNA directly from soils. Appl Environ Microbiol 65, 5409-5420.

682

683

684

685

686

687

688

689

690

691

692

693

694

695

696

697

698

699

700

701

702

703

704

705

706

707

708

709

710

711

712

713

714

715

716

717

718

719

720

721

722

723

724

725

726

727

728

729

730

731

732

733
Gans, J., Wolinsky, M., Dunbar, J., 2005. Computational improvements reveal great bacterial diversity and high metal toxicity in soil. Science 309, 1387-1390.

Hamady, M., Lozupone, C., Knight, R., 2010. Fast UniFrac: facilitating highthroughput phylogenetic analyses of microbial communities including analysis of pyrosequencing and PhyloChip data. Isme J 4, 17-27.

Hawksworth, D.L., Rossman, A.Y., 1997. Where are all the undescribed fungi? Phytopathology 87, 888-891.

Hill, T.C.J., Walsh, K.A., Harris, J.A., Moffett, B.F., 2003. Using ecological diversity measures with bacterial communities. FEMS Microbiol Ecol 43, 1-11.

Inceoglu, O., Hoogwout, E.F., Hill, P., van Elsas, J.D., 2010. Effect of DNA Extraction Method on the Apparent Microbial Diversity of Soil. Appl Environ Microb 76, 33783382.

Jones, M.D., Singleton, D.R., Sun, W., Aitken, M.D., 2011. Multiple DNA Extractions Coupled with Stable-Isotope Probing of Anthracene-Degrading Bacteria in Contaminated Soil. Appl Environ Microb 77, 2984-2991.

Jones, S.E., Lennon, J.T., 2010. Dormancy contributes to the maintenance of microbial diversity. Proceedings of the National Academy of Sciences 107, 58815886.

Knauth, S., Schmidt, H., Tippkotter, R., 2013. Comparison of commercial kits for the extraction of DNA from paddy soils. Lett Appl Microbiol 56, 222-228.

Koster, J., Rahmann, S., 2012. Snakemake--a scalable bioinformatics workflow engine. Bioinformatics 28, 2520-2522.

Kuramae, E.E., Yergeau, E., Wong, L.C., Pijl, A.S., van Veen, J.A., Kowalchuk, G.A., 2012. Soil characteristics more strongly influence soil bacterial communities than land-use type. FEMS Microbiol Ecol 79, 12-24.

Leite, D.C., Balieiro, F.C., Pires, C.A., Madari, B.E., Rosado, A.S., Coutinho, H.L., Peixoto, R.S., 2014. Comparison of DNA extraction protocols for microbial communities from soil treated with biochar. Braz J Microbiol 45, 175-183.

Liles, M.R., Williamson, L.L., Rodbumrer, J., Torsvik, V., Goodman, R.M., Handelsman, J., 2008. Recovery, purification, and cloning of high-molecular-weight DNA from soil microorganisms. Appl Environ Microbiol 74, 3302-3305.

Lombard, N., Prestat, E., van Elsas, J.D., Simonet, P., 2011. Soil-specific limitations for access and analysis of soil microbial communities by metagenomics. FEMS Microbiol Ecol 78, 31-49.

Maphosa, F., Lieten, S.H., Dinkla, I., Stams, A.J., Smidt, H., Fennell, D.E., 2012. Ecogenomics of microbial communities in bioremediation of chlorinated contaminated sites. Frontiers in microbiology 3, 351. 
734 Martin-Laurent, F., Philippot, L., Hallet, S., Chaussod, R., Germon, J.C., Soulas, G., 735 Catroux, G., 2001. DNA extraction from soils: Old bias for new microbial diversity analysis methods. Appl Environ Microb 67, 2354-2359.

McDonald, D., Clemente, J., Kuczynski, J., Rideout, J., Stombaugh, J., Wendel, D., Wilke, A., Huse, S., Hufnagle, J., Meyer, F., Knight, R., Caporaso, J., 2012. The Biological Observation Matrix (BIOM) format or: how I learned to stop worrying and love the ome-ome. GigaScience 1, 7.

McMurdie, P.J., Holmes, S., 2013. phyloseq: an R package for reproducible interactive analysis and graphics of microbiome census data. Plos One 8, e61217.

McMurdie, P.J., Holmes, S., 2014. Waste not, want not: why rarefying microbiome data is inadmissible. Plos Comput Biol 10, e1003531.

Mendes, L.W., Kuramae, E.E., Navarrete, A.A., van Veen, J.A., Tsai, S.M., 2014. Taxonomical and functional microbial community selection in soybean rhizosphere. Isme J.

Mendes, L.W., Taketani, R.G., Navarrete, A.A., Tsai, S.M., 2012. Shifts in phylogenetic diversity of archaeal communities in mangrove sediments at different sites and depths in southeastern Brazil. Research in microbiology 163, 366-377.

Mendes, R., Garbeva, P., Raaijmakers, J.M., 2013. The rhizosphere microbiome: significance of plant beneficial, plant pathogenic, and human pathogenic microorganisms. Fems Microbiol Rev 37, 634-663.

Mendes, R., Kruijt, M., de Bruijn, I., Dekkers, E., van der Voort, M., Schneider, J.H.M., Piceno, Y.M., DeSantis, T.Z., Andersen, G.L., Bakker, P.A.H.M., Raaijmakers, J.M., 2011. Deciphering the Rhizosphere Microbiome for DiseaseSuppressive Bacteria. Science 332, 1097-1100.

Navarrete, A.A., Tsai, S.M., Mendes, L.W., Faust, K., de Hollander, M., Cassman, N.A., Raes, J., van Veen, J.A., Kuramae, E.E., 2015. Soil microbiome responses to the short-term effects of Amazonian deforestation. Molecular ecology 24, 2433-2448.

Pan, Y., Cassman, N., de Hollander, M., Mendes, L.W., Korevaar, H., Geerts, R.H.E.M., van Veen, J.A., Kuramae, E.E., 2014. Impact of long-term N, P, K, and NPK fertilization on the composition and potential functions of the bacterial community in grassland soil. FEMS Microbiol Ecol 90, 195-205.

Pietramellara, G., Franchi, M., Gallori, E., Nannipieri, P., 2001. Effect of molecular characteristics of DNA on its adsorption and binding on homoionic montmorillonite and kaolinite. Biol Fert Soils 33, 402-409.

Pruesse, E., Peplies, J., Glockner, F.O., 2012. SINA: accurate high-throughput multiple sequence alignment of ribosomal RNA genes. Bioinformatics 28, 1823-1829.

Quast, C., Pruesse, E., Yilmaz, P., Gerken, J., Schweer, T., Yarza, P., Peplies, J., Glockner, F.O., 2013. The SILVA ribosomal RNA gene database project: improved data processing and web-based tools. Nucleic Acids Res 41, D590-596.

Quince, C., Lanzen, A., Davenport, R.J., Turnbaugh, P.J., 2011. Removing noise from pyrosequenced amplicons. BMC bioinformatics 12, 38 . 
789 Robe, P., Nalin, R., Capellano, C., Vogel, T.A., Simonet, P., 2003. Extraction of DNA 790 from soil. Eur J Soil Biol 39, 183-190.

791

792

793

794

795

796

797

798

799

800

801

802

803

804

805

806

807

808

809

810

811

812

813

814

815

816

817

818

819

820

821

822

823

824

825

826

827

828

829

830

831

832

833

834

835

836

837

838

839

840

841

842

843

Romanowski, G., Lorenz, M.G., Wackernagel, W., 1993. Plasmid DNA in a groundwater aquifer microcosm -adsorption, DNAase resistance and natural genetic transformation of Bacillus subtilis. Molecular ecology 2, 171-181.

Schloss, P.D., Westcott, S.L., Ryabin, T., Hall, J.R., Hartmann, M., Hollister, E.B., Lesniewski, R.A., Oakley, B.B., Parks, D.H., Robinson, C.J., Sahl, J.W., Stres, B., Thallinger, G.G., Van Horn, D.J., Weber, C.F., 2009. Introducing mothur: opensource, platform-independent, community-supported software for describing and comparing microbial communities. Appl Environ Microbiol 75, 7537-7541.

Sheneman, L., Evans, J., Foster, J.A., 2006. Clearcut: a fast implementation of relaxed neighbor joining. Bioinformatics 22, 2823-2824.

Sutton, N.B., Maphosa, F., Morillo, J.A., Abu Al-Soud, W., Langenhoff, A.A., Grotenhuis, T., Rijnaarts, H.H., Smidt, H., 2013. Impact of long-term diesel contamination on soil microbial community structure. Appl Environ Microbiol 79, 619630.

Suzuki, M.T., Taylor, L.T., DeLong, E.F., 2000. Quantitative analysis of small-subunit rRNA genes in mixed microbial populations via 5'-nuclease assays. Appl Environ Microbiol 66, 4605-4614.

Tahir, M., Mirza, M.S., Hameed, S., Dimitrov, M.R., Smidt, H., 2015. CultivationBased and Molecular Assessment of Bacterial Diversity in the Rhizosheath of Wheat under Different Crop Rotations. Plos One 10, e0130030.

ter Braak, C.J.F., Šmilauer, P., 2002. CANOCO Reference Manual and CanoDraw for Windows User's Guide: Software for Canonical Community Ordination (version 4.5). Microcomputer Power, Ithaca, NY, USA.

R-Core Team., 2014. R: A Language and Environment for Statistical Computing. R Foundation for Statistical Computing, Vienna, Austria.

Torsvik, V., Goksøyr, J., Daae, F.L., 1990. High diversity in DNA of soil bacteria. Appl Environ Microb 56, 782-787.

Torsvik, V., Øvreås, L., 2002. Microbial diversity and function in soil: from genes to ecosystems. Current opinion in microbiology 5, 240-245.

Torsvik, V., Øvreås, L., Thingstad, T.F., 2002. Prokaryotic Diversity--Magnitude, Dynamics, and Controlling Factors. Science 296, 1064-1066.

Vainio, E.J., Hantula, J., 2000. Direct analysis of wood-inhabiting fungi using denaturing gradient gel electrophoresis of amplified ribosomal DNA. Mycological research 104, 927-936.

Vishnivetskaya, T.A., Layton, A.C., Lau, M.C.Y., Chauhan, A., Cheng, K.R., Meyers, A.J., Murphy, J.R., Rogers, A.W., Saarunya, G.S., Williams, D.E., Pfiffner, S.M., Biggerstaff, J.P., Stackhouse, B.T., Phelps, T.J., Whyte, L., Sayler, G.S., Onstott, T.C., 2014. Commercial DNA extraction kits impact observed microbial community composition in permafrost samples. FEMS Microbiol Ecol 87, 217-230.

Peer] reviewing PDF | (2016:06:11533:1:0:CHECK 24 Nov 2016) 
844 White, T.J., Bruns, T., Lee, S., Taylor, J., 1990. Amplification and direct sequencing 845 of fungal ribosomal RNA genes for phylogenetics, in: Innis, M.A., Gelfand, D.H., 846 Sninsky, J.J., White, T.J. (Eds.), PCR protocols : a guide to methods and 847 applications. Academic Press, San Diego ; London, pp. 315-322.

848

849 Wilson, I.G., 1997. Inhibition and facilitation of nucleic acid amplification. Appl 850 Environ Microbiol 63, 3741-3751.

851

852

Zhou, J., Bruns, M.A., Tiedje, J.M., 1996. DNA recovery from soils of diverse 853 composition. Appl Environ Microbiol 62, 316-322.

854 
855 Figures and Tables 
Power Soil bead tube containing

$0.25 \mathrm{~g}$ of soil and solution $\mathrm{C} 1$.

Tubes were subjected to bead-

beating step at $5.5 \mathrm{~m} \mathrm{~s}-1$ for 10

min.

Centrifugation

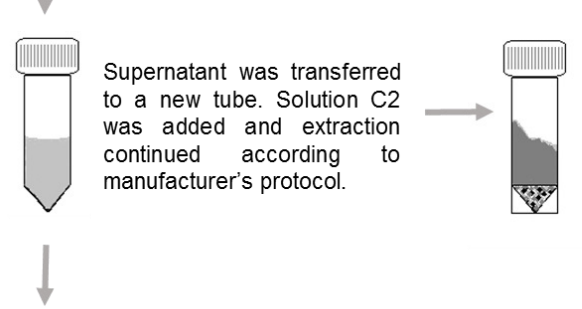

E1

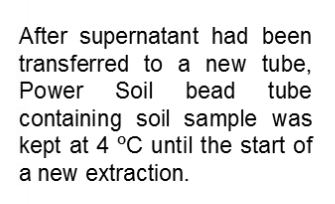

After supernatant had been transferred to a new tube, Power Soil bead tube containing soil sample was kept at $4{ }^{\circ} \mathrm{C}$ until the start of a new extraction.

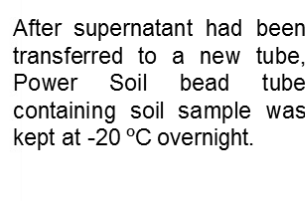
transferred to a new tube, containing soil sample was to a new tube. Solution $\mathrm{C} 2$ was added and extraction continued according
manufacturer's protocol.
Figure 1. Successive DNA extraction procedure. Scheme represents extraction performed with the PowerSoil DNA isolation kit (PS). Same procedure was used for FastDNA Spin kit for soil (FS), however, the amount of soil and bead-beating step were different. 
859 Table 1. Adaptors and primers used for targeting prokaryotic and fungal community.

\begin{tabular}{|c|c|c|c|c|c|}
\hline Primers & Sequence 5'- 3' & Target & Application & Cycle conditions & References \\
\hline ITS1F & TCCGTAGGTGAACCTGCGG & Fungi & T-RFLP & $\begin{array}{l}95^{\circ} \mathrm{C}-5 \mathrm{~min} ; 35 \text { cycles of } 95^{\circ} \mathrm{C}- \\
30 \mathrm{sec}, 55^{\circ} \mathrm{C}-40 \text { sec, } 72^{\circ} \mathrm{C}-90\end{array}$ & White et al. (1990) \\
\hline ITS4R & TCCTCCGCTTATTGATATGC & Fungi & T-RFLP & sec & White et al. (1990) \\
\hline BACT1369F & CGGTGAATACGTTCYCGG & Bacteria & qPCR & $95^{\circ} \mathrm{C}-3 \mathrm{~min} ; 40$ cycles of $95^{\circ} \mathrm{C}-30$ & Suzuki et al. (2000) \\
\hline PROK1492R & GGWTACCTTGTTACGACTT & Bacteria & qPCR & $\mathrm{sec}, 56{ }^{\circ} \mathrm{C}-45 \mathrm{sec}, 72{ }^{\circ} \mathrm{C} 60 \mathrm{sec}$ & Suzuki et al. (2000) \\
\hline FF390 & CGWTAACGAACGAGACCT & Fungi & qPCR & $\begin{array}{c}95^{\circ} \mathrm{C}-3 \mathrm{~min} ; 40 \text { cycles of } 95^{\circ} \mathrm{C}-30 \\
\text { sec, } 52{ }^{\circ} \mathrm{C}-45 \mathrm{sec}, 72^{\circ} \mathrm{C}-60 \mathrm{sec}\end{array}$ & $\begin{array}{l}\text { Modified from Vainio and } \\
\text { Hantula (2000) }\end{array}$ \\
\hline FFR1 & AICCATTCAATCGGTAIT & Fungi & qPCR & & Vainio and Hantula (2000) \\
\hline $515 \mathrm{~F}$ & GTGCCAGCMGCCGCGGTAA & $\begin{array}{l}\text { Archaea } \\
\text { and }\end{array}$ & Sequencing & & Bates et al. (2011) \\
\hline 806R & GGACTACVSGGGTATCTAAT & $\begin{array}{l}\text { Bacteria } \\
\text { Archaea } \\
\text { and } \\
\text { Bacteria }\end{array}$ & Sequencing & $\begin{array}{l}95^{\circ} \mathrm{C}-2 \mathrm{~min} ; 25 \text { cycles of } 95^{\circ} \mathrm{C}-30 \\
\text { sec, } 53^{\circ} \mathrm{C}-45 \mathrm{sec}, 72^{\circ} \mathrm{C} 60 \mathrm{sec} .\end{array}$ & Bates et al. (2011) \\
\hline FF390 & CGWTAACGAACGAGACCT & Fungi & Sequencing & $\begin{array}{c}95^{\circ} \mathrm{C}-2 \mathrm{~min} ; 25 \text { cycles of } 95^{\circ} \mathrm{C}-30 \\
\text { sec, } 52^{\circ} \mathrm{C}-45 \mathrm{sec}, 72^{\circ} \mathrm{C}-60 \mathrm{sec}\end{array}$ & $\begin{array}{l}\text { Modified from Vainio and } \\
\text { Hantula (2000) }\end{array}$ \\
\hline FR1 & AICCATTCAATCGGTAIT & Fungi & Sequencing & & Vainio and Hantula (2000) \\
\hline
\end{tabular}

860 
861
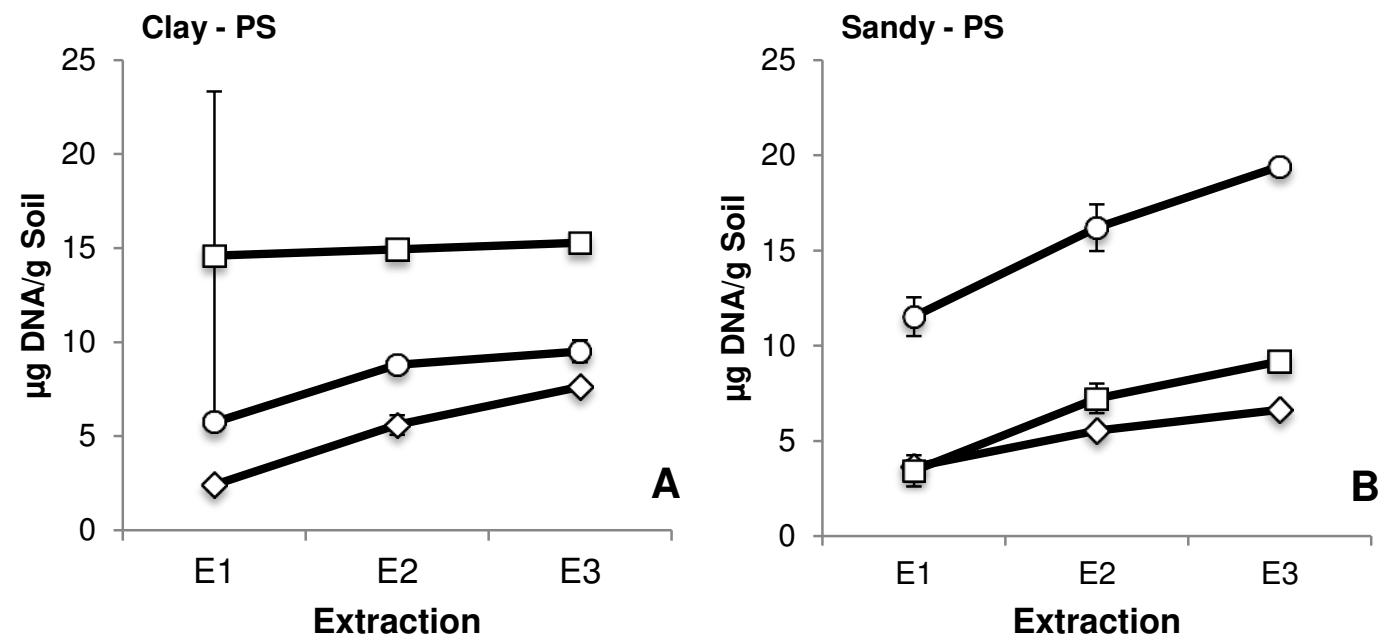

862
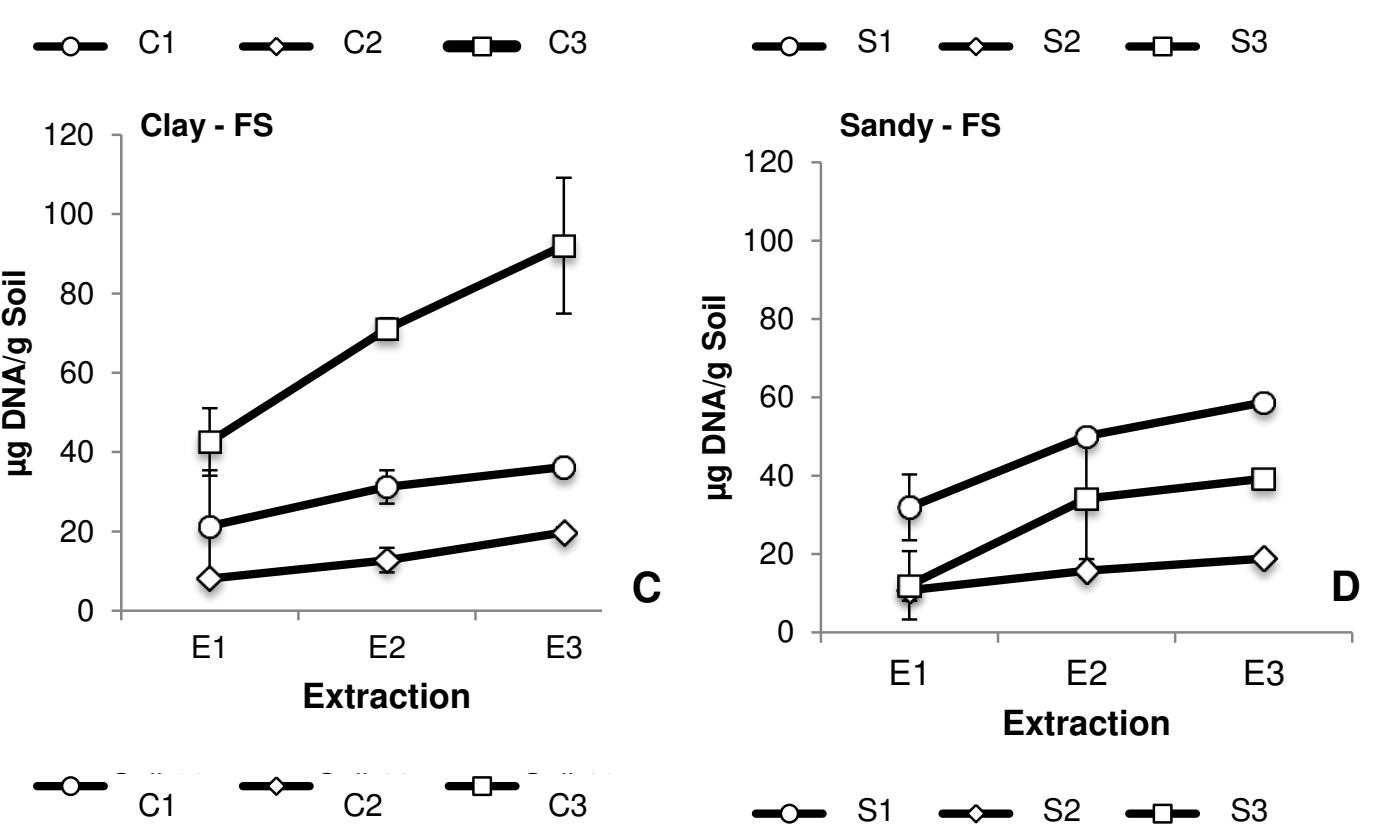

863

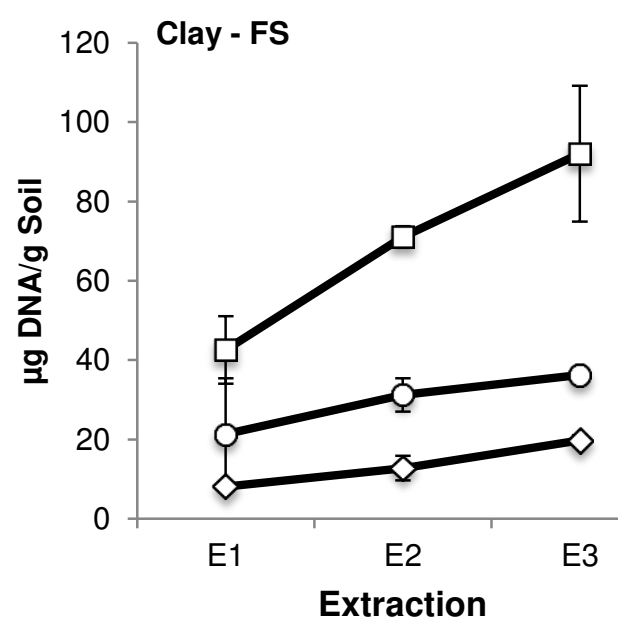

864 Figure 2. Cumulative DNA yields in successive extractions of clay (C1-C3) and 865 sandy soils (S1-S3) using PS and FS DNA extraction kits. Average and error bars 866 (SD) of all three biological replicates are presented for each DNA extraction. (A) clay 867 soils extracted with PS; (B) sandy soils extracted with PS; (C) clay soils extracted 868 with FS; (D) sandy soils extracted with FS. DNA quantification was performed using 869 a Qubit 2.0 fluorometer. 
870
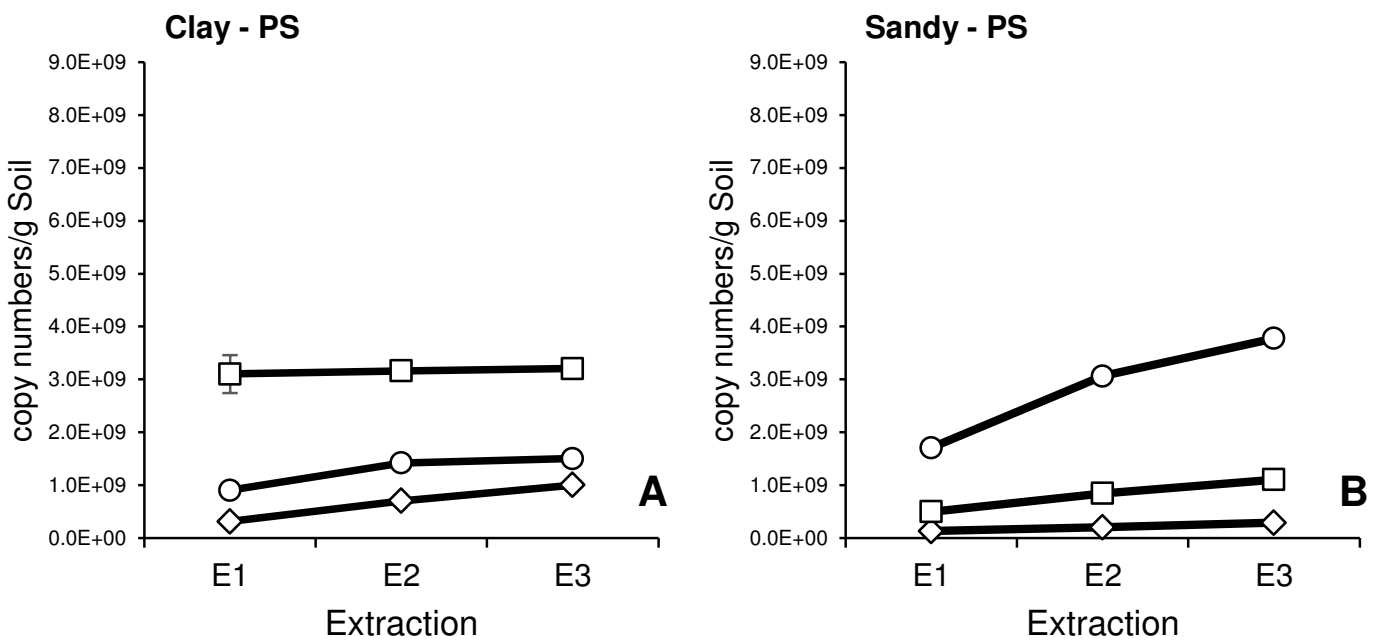

871
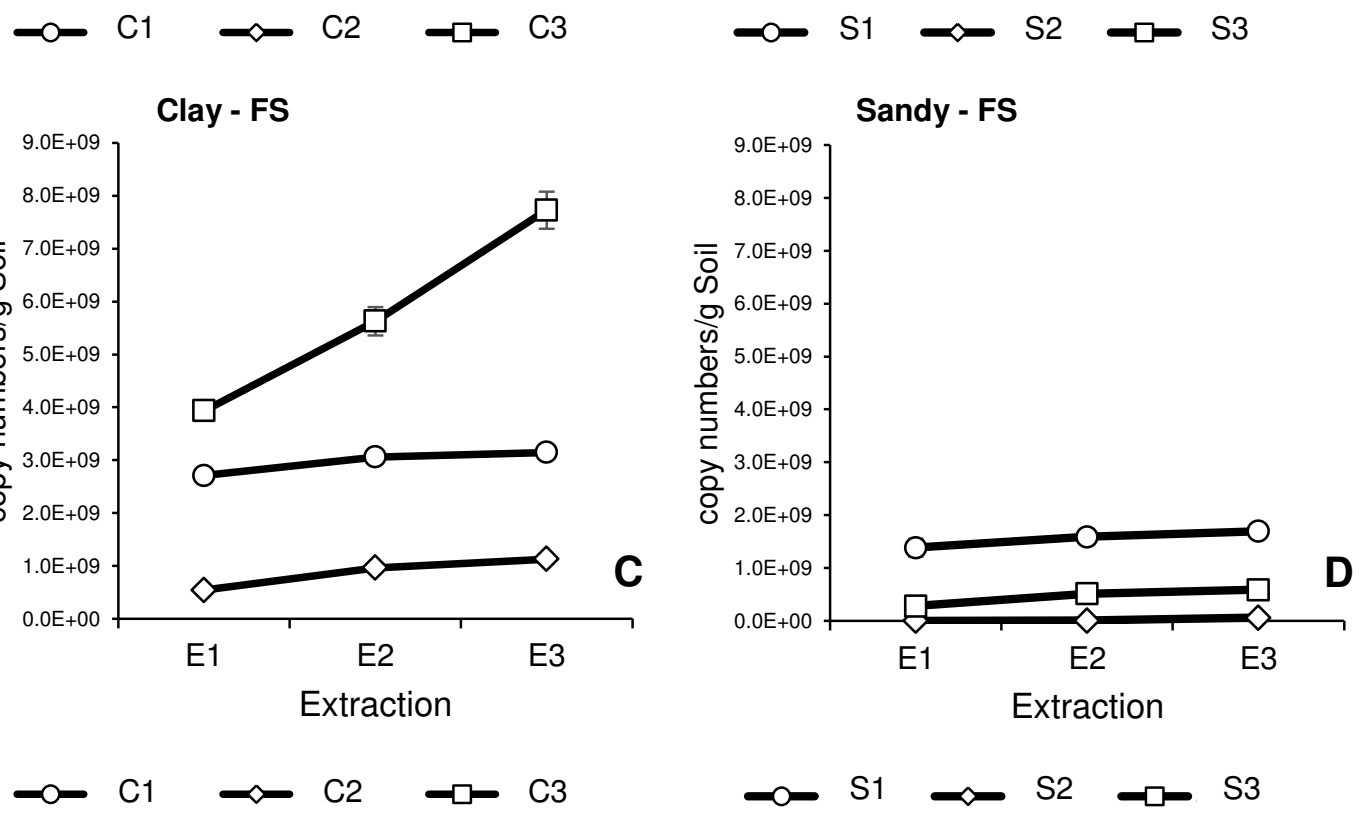

872

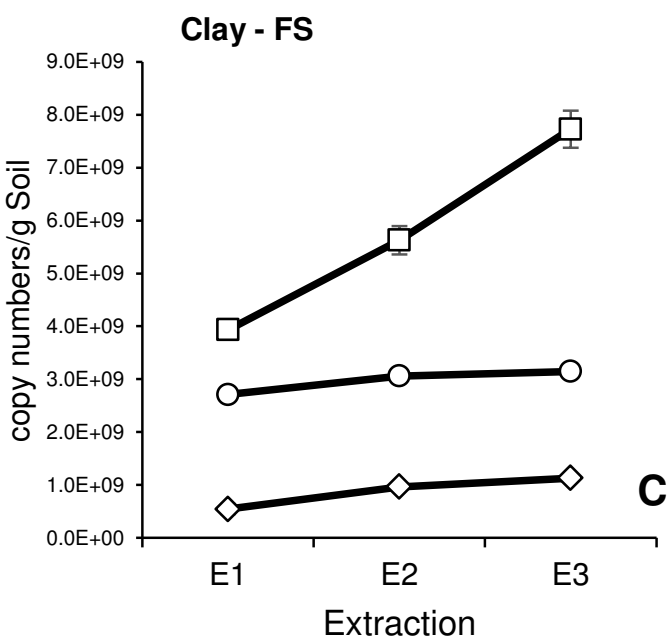

873 Figure 3. Cumulative 16S rRNA copy numbers in successive extractions of clay (C1-

874 C3) and sandy soils (S1-S3) using PS and FS DNA extraction kits. Average and error

875 bars (SD) of all three technical replicates are presented for each DNA extraction. (A)

876 clay soils extracted with PS; (B) sandy soils extracted with PS; (C) clay soils

877 extracted with FS; (D) sandy soils extracted with FS. 


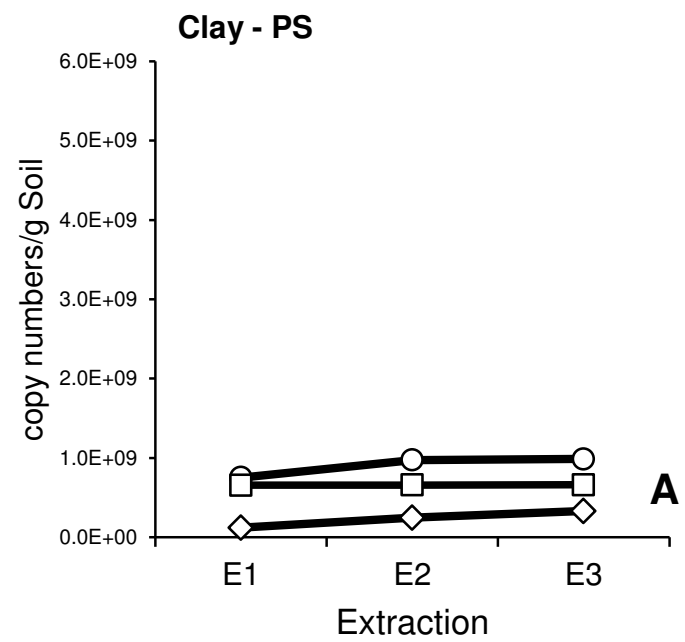

\section{Manuscript to be reviewed}

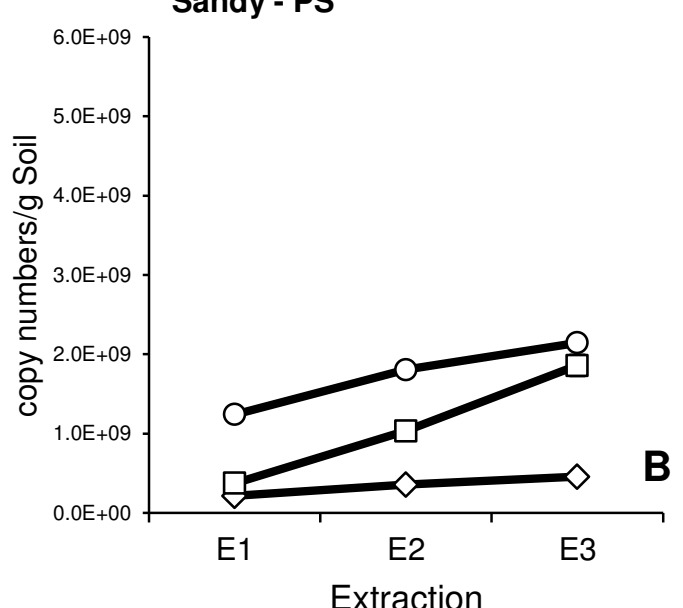

878
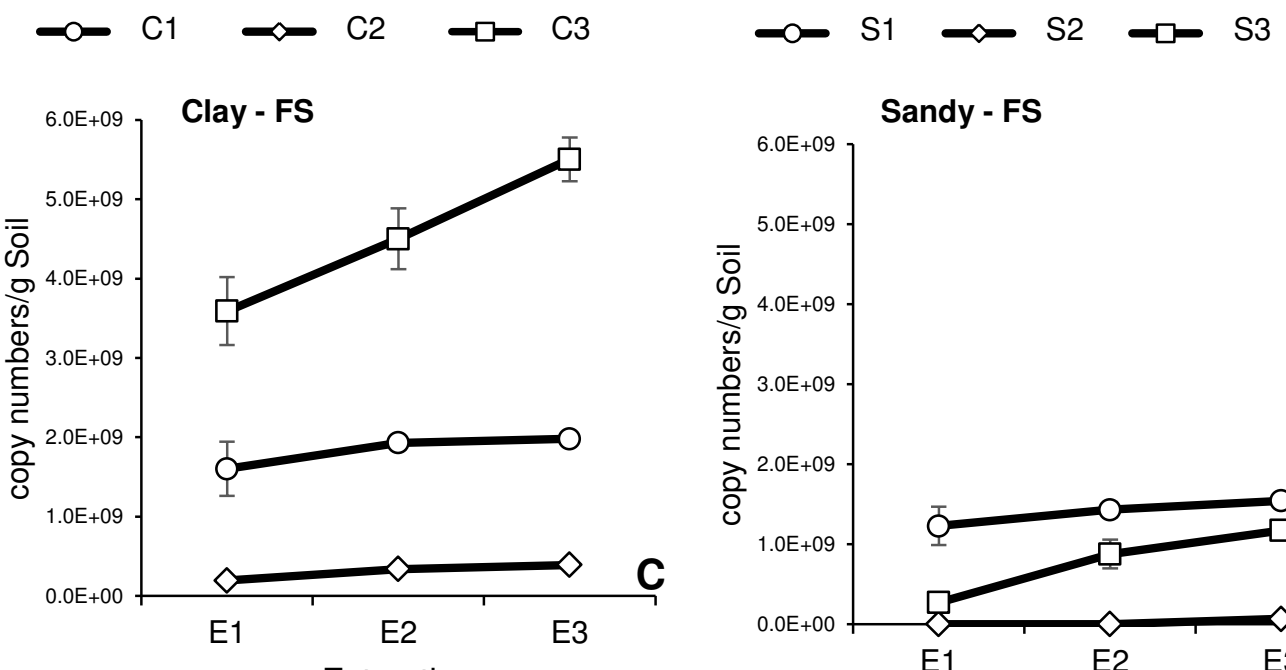

Extraction

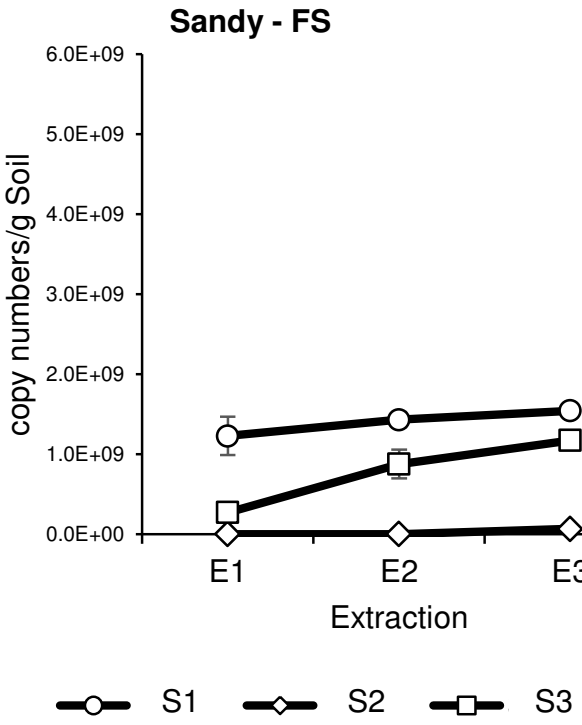

879

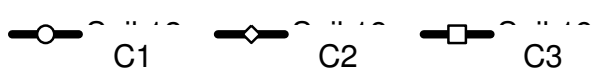

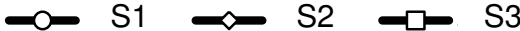

880 Figure 4. Cumulative 18S rRNA copy numbers in successive extractions of clay (C1881 C3) and sandy soils (S1-S3) using PS and FS DNA extraction kits. Average and error 882 bars (SD) of all three technical replicates are presented for each DNA extraction. (A) 883 clay soils extracted with PS; (B) sandy soils extracted with PS; (C) clay soils 884 extracted with FS; (D) sandy soils extracted with FS. 


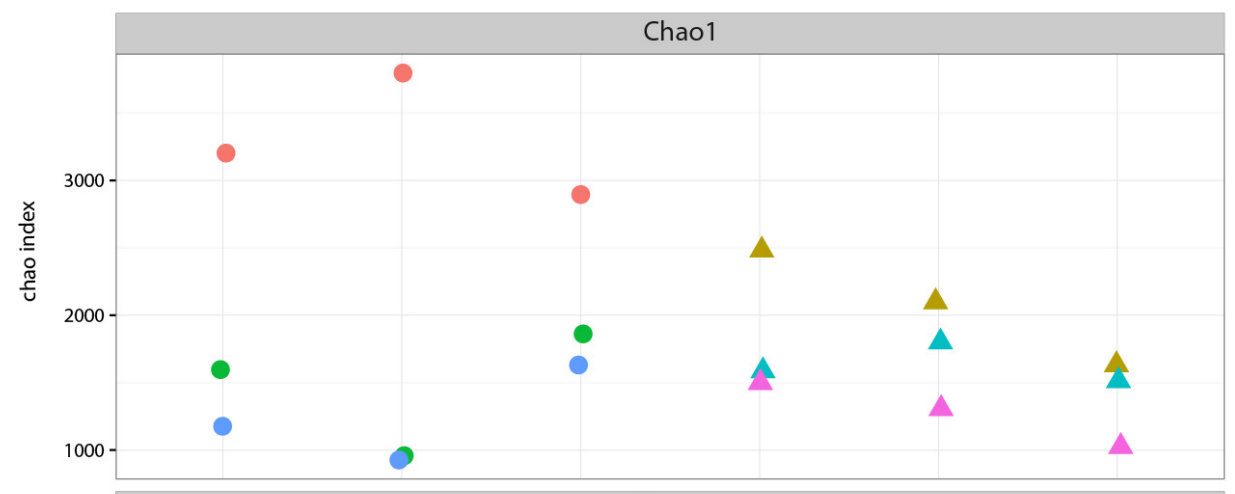

ExtractionKit

- FastDNASpin

A PowerSoil

factor(SoilKit)

clay 1_FS

clay 1_PS

clay 2_FS

clay 2_PS

clay 3_FS

- clay 3_PS

885

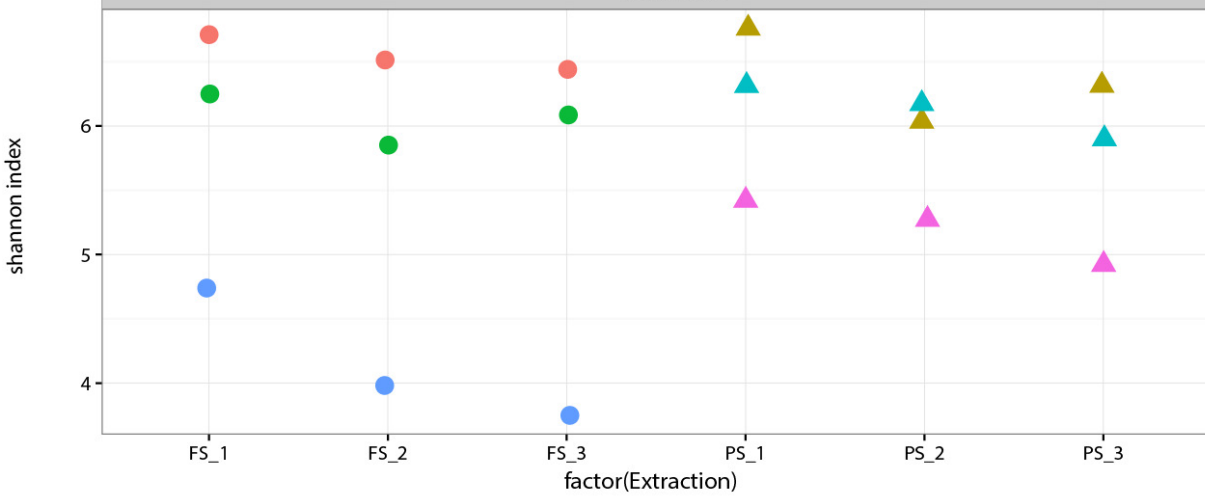

A

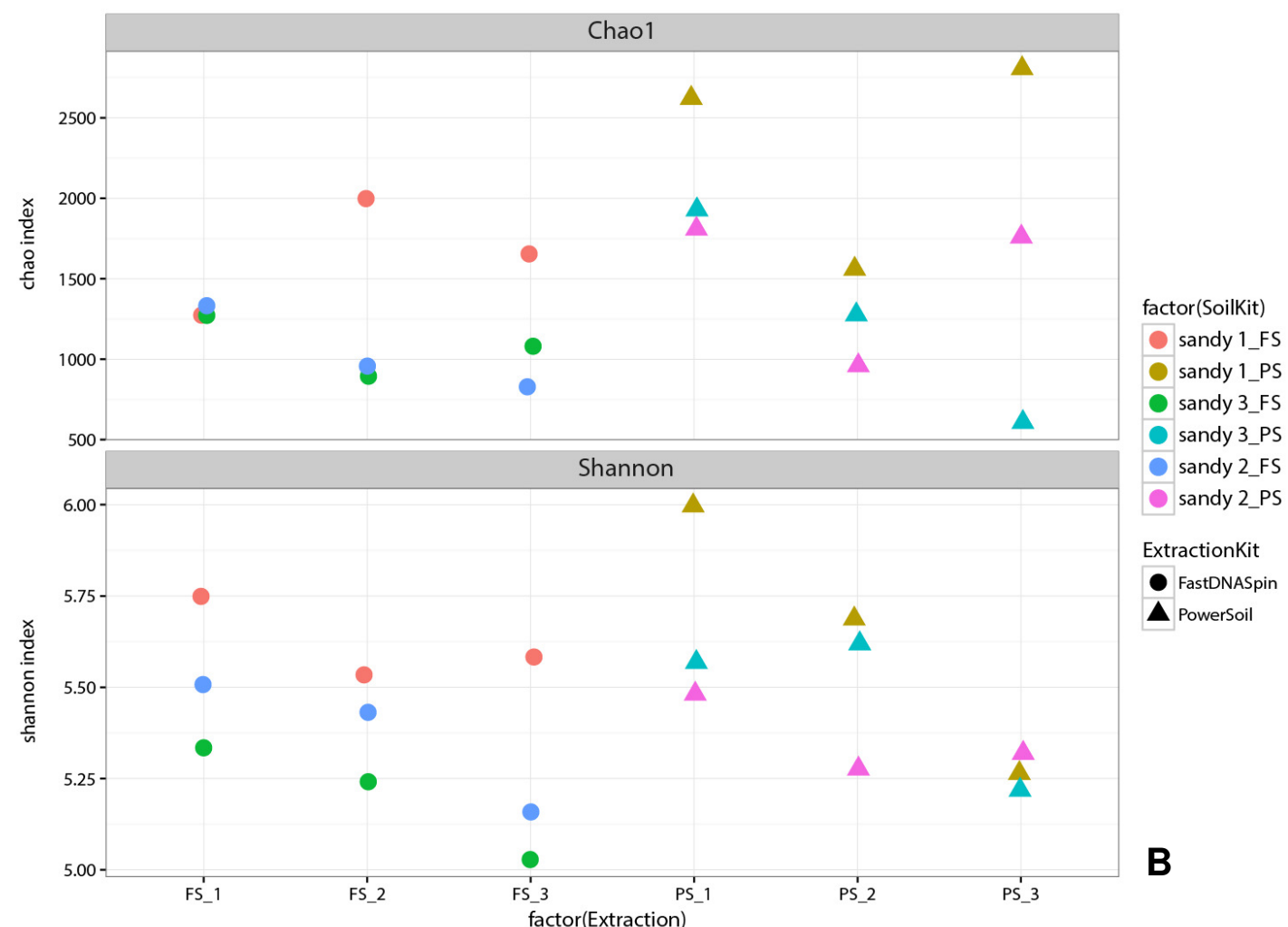

886

887 Figure 5. Species richness (Chao1) and diversity (Shannon) of the prokaryotic 888 community in clay (A) and sandy (B) soils. 


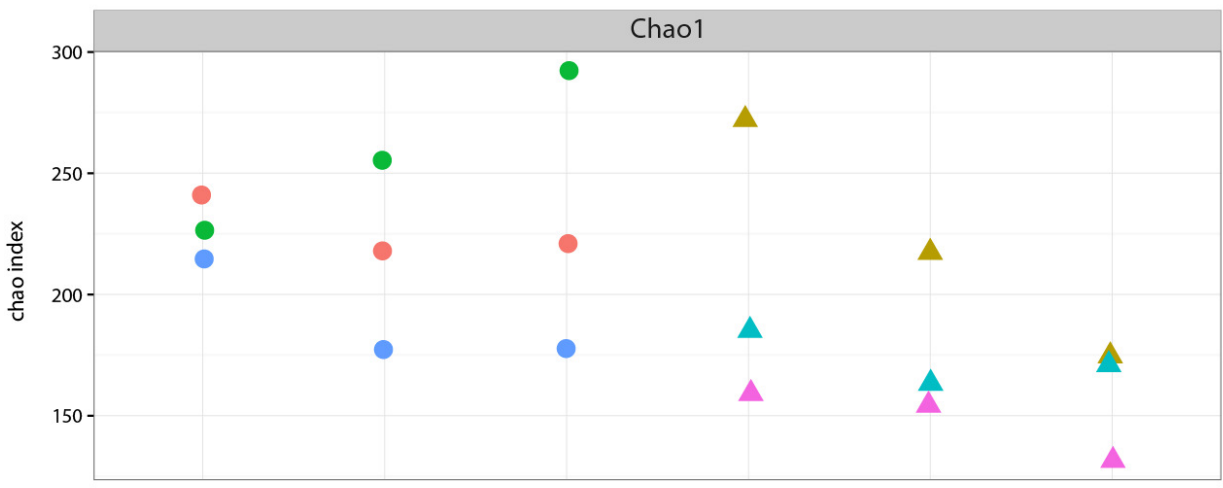

ExtractionKit

- FastDNASpin

$\Delta$ PowerSoil

factor(SoilKit)

- clay 1_FS

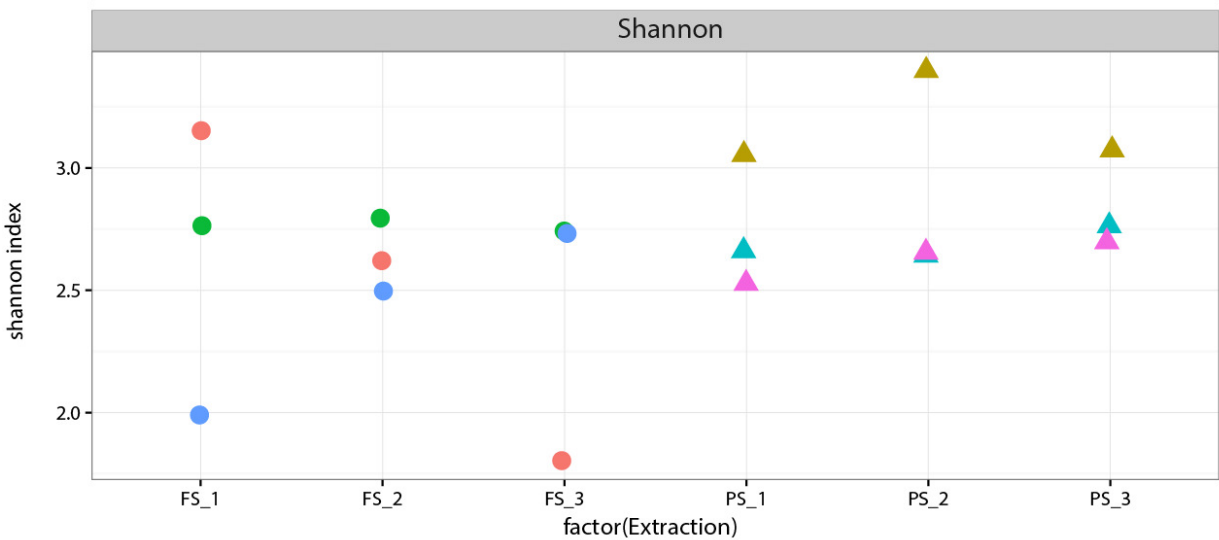

- clay 1_PS

clay 2_FS

clay 2_PS

- clay 3_FS

- clay 3_PS

A

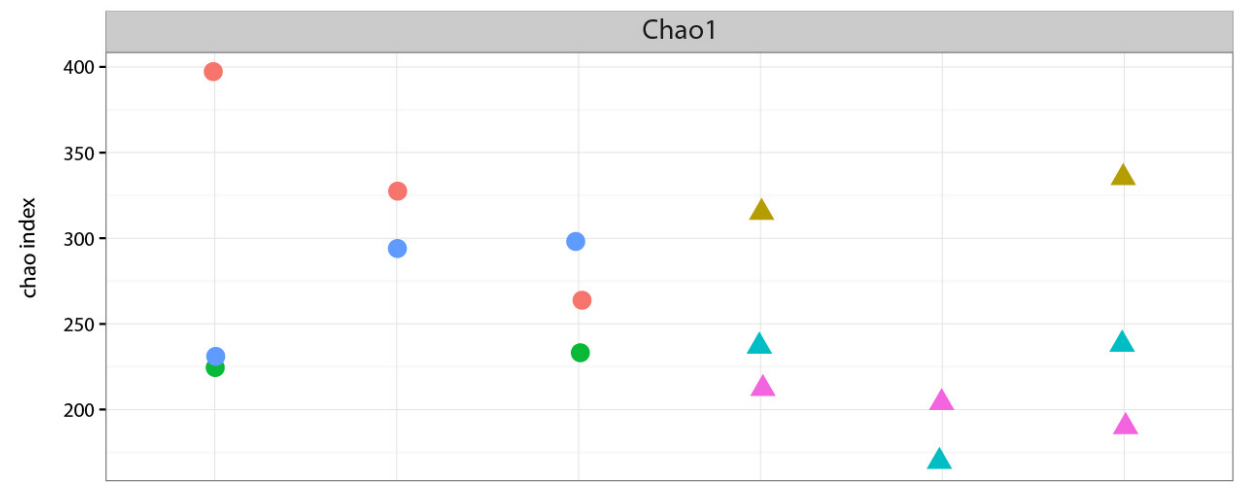

factor(SoilKit)

sandy 1_FS

sandy 1_PS

- sandy 3_FS

sandy 3_PS

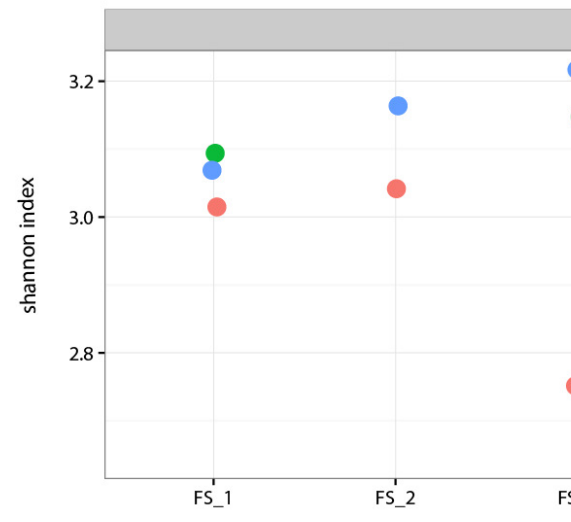

Shannon

- sandy 2_FS

sandy 2_PS

ExtractionKit

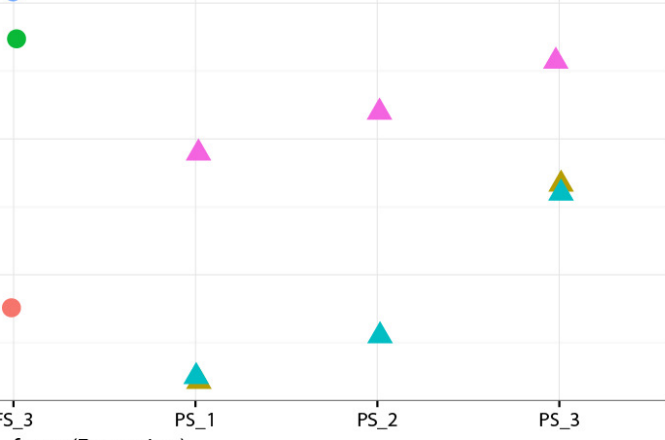

- FastDNASpin

A PowerSoil

B

890

factor(Extraction)

891 Figure 6. Species richness (Chao1) and diversity (Shannon) of the fungal community 892 in clay (A) and sandy (B) soils. 
893

894
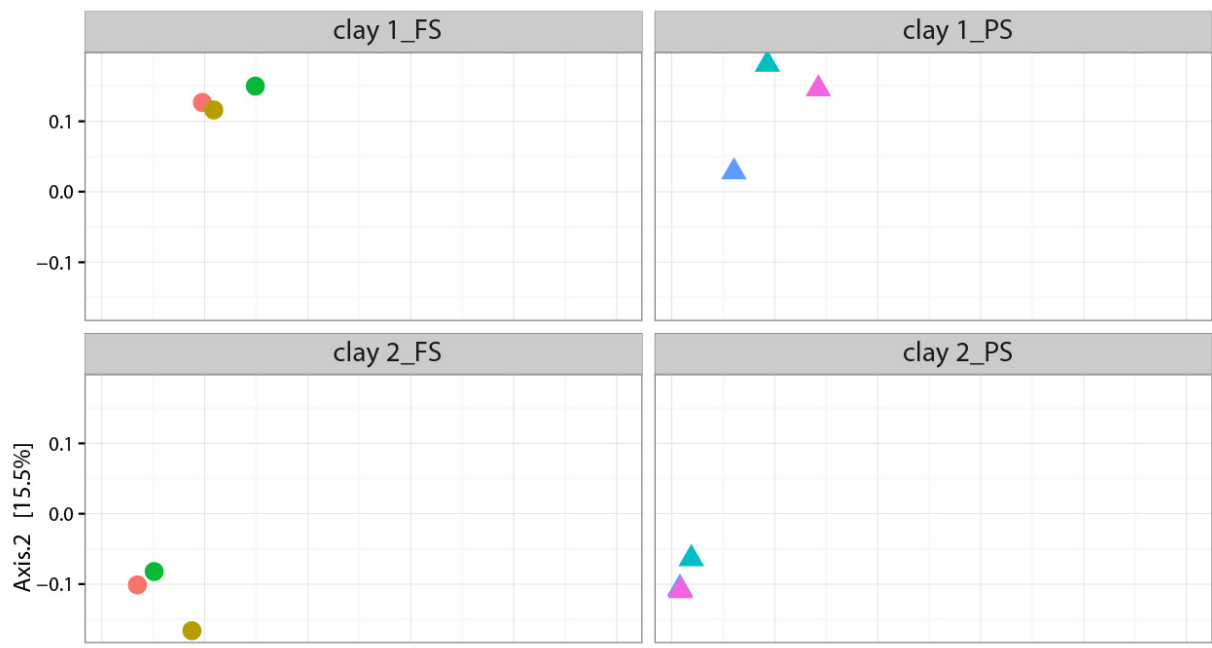

Extraction

- FS_1

- FS_2

- FS_3

- PS_1

- PS_2

- PS_3

ExtractionKit

- FastDNASpin

clay 3_FS

clay 3_PS

$\Delta$ PowerSoil

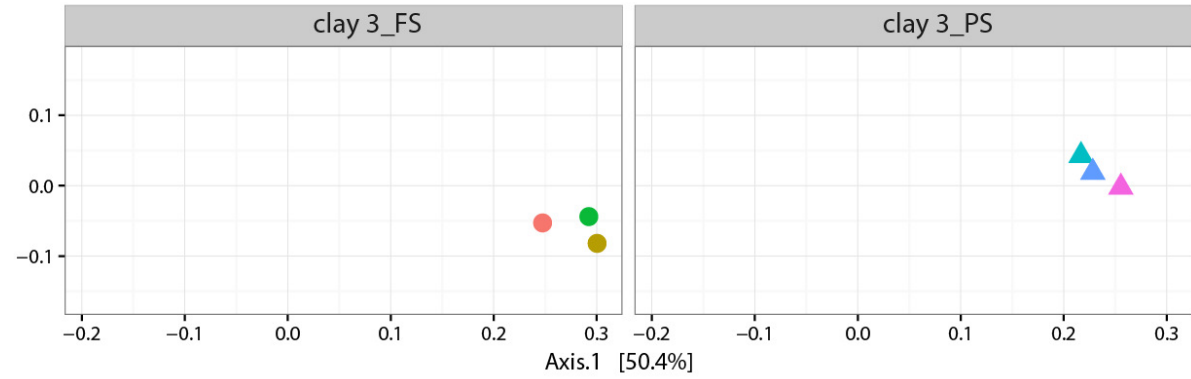

A
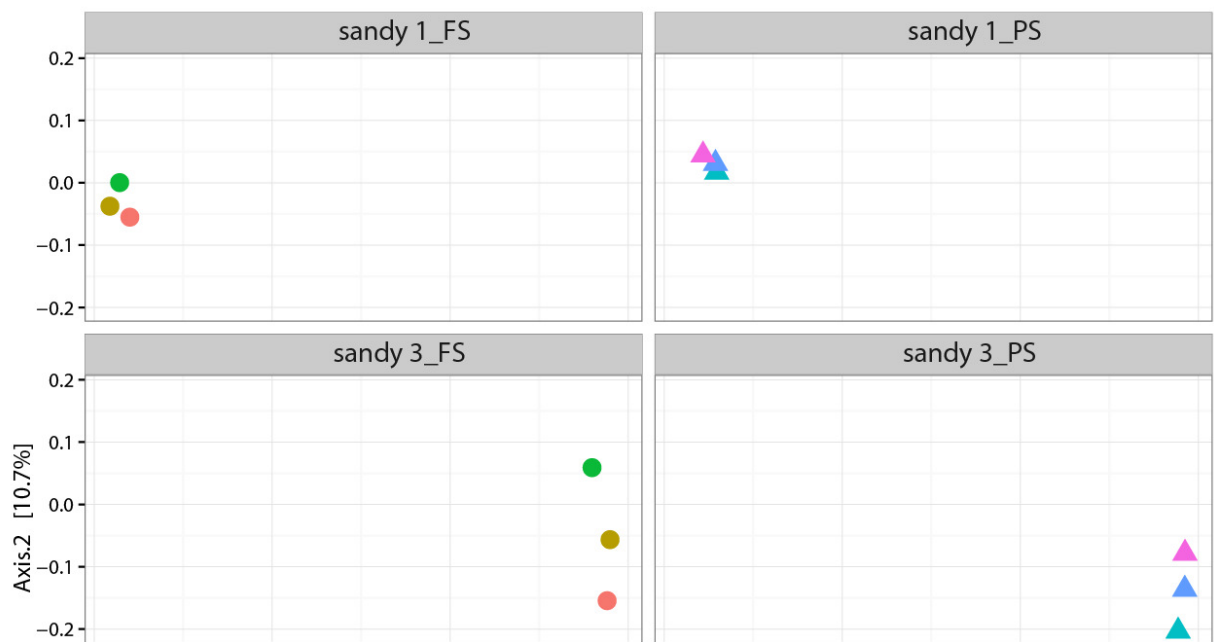

Extraction

- FS_1

- FS_2

FS_3

- PS_1

PS 2

- PS_3

ExtractionKit

- FastDNASpin

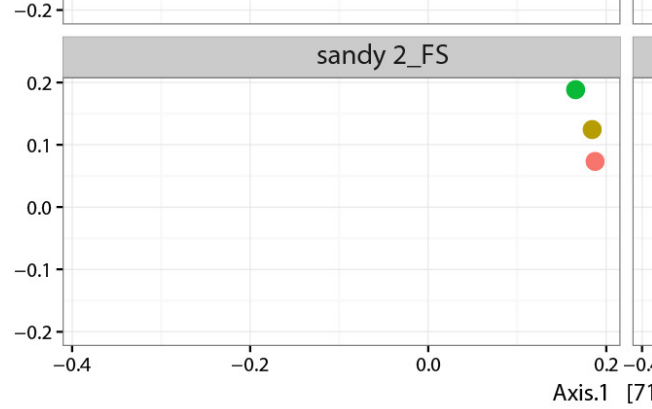

$\Delta$ Powersoil

895 xis.1 [71\%]

B

896 Figure 7. Multidimensional scaling (MDS) analysis of weighted Unifrac values from 897 prokaryotic community in clay $(A)$ and sandy soils $(B)$. 

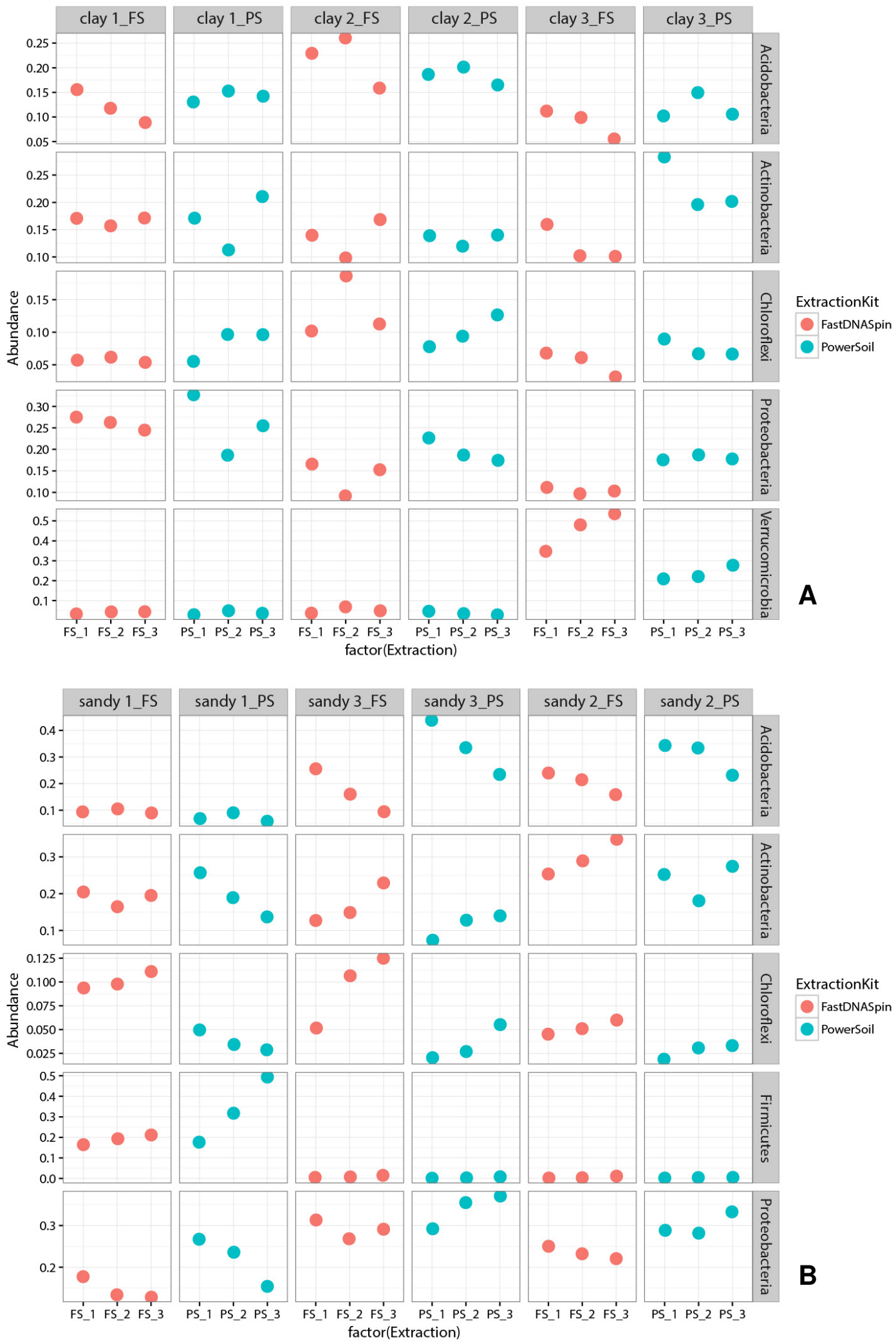

900 Figure 8. Relative abundance of the five most abundant prokaryotic taxa found in 901 clay (A) and sandy (B) soils. Abundance is depicted as percentage, where one (1.0) 902 corresponds to the sum of all taxa found. 

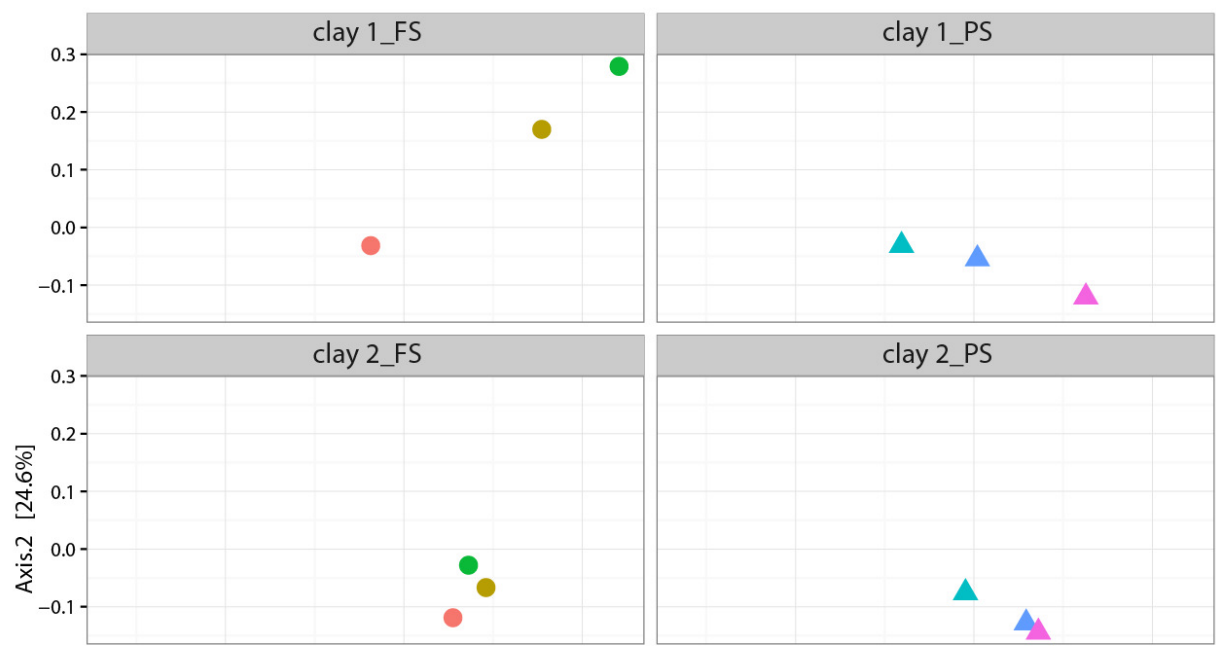

Extraction

FS_1

- FS_2

- FS_3

- PS_1

PS_2

- PS_3

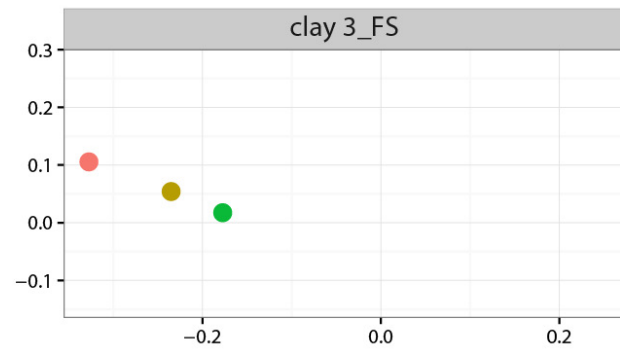

clay 3_PS

- FastDNASpin

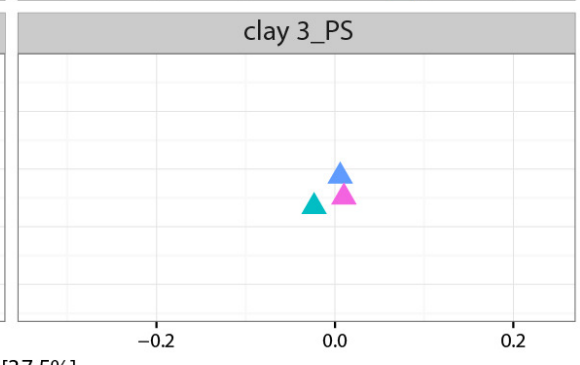

A PowerSoil

A

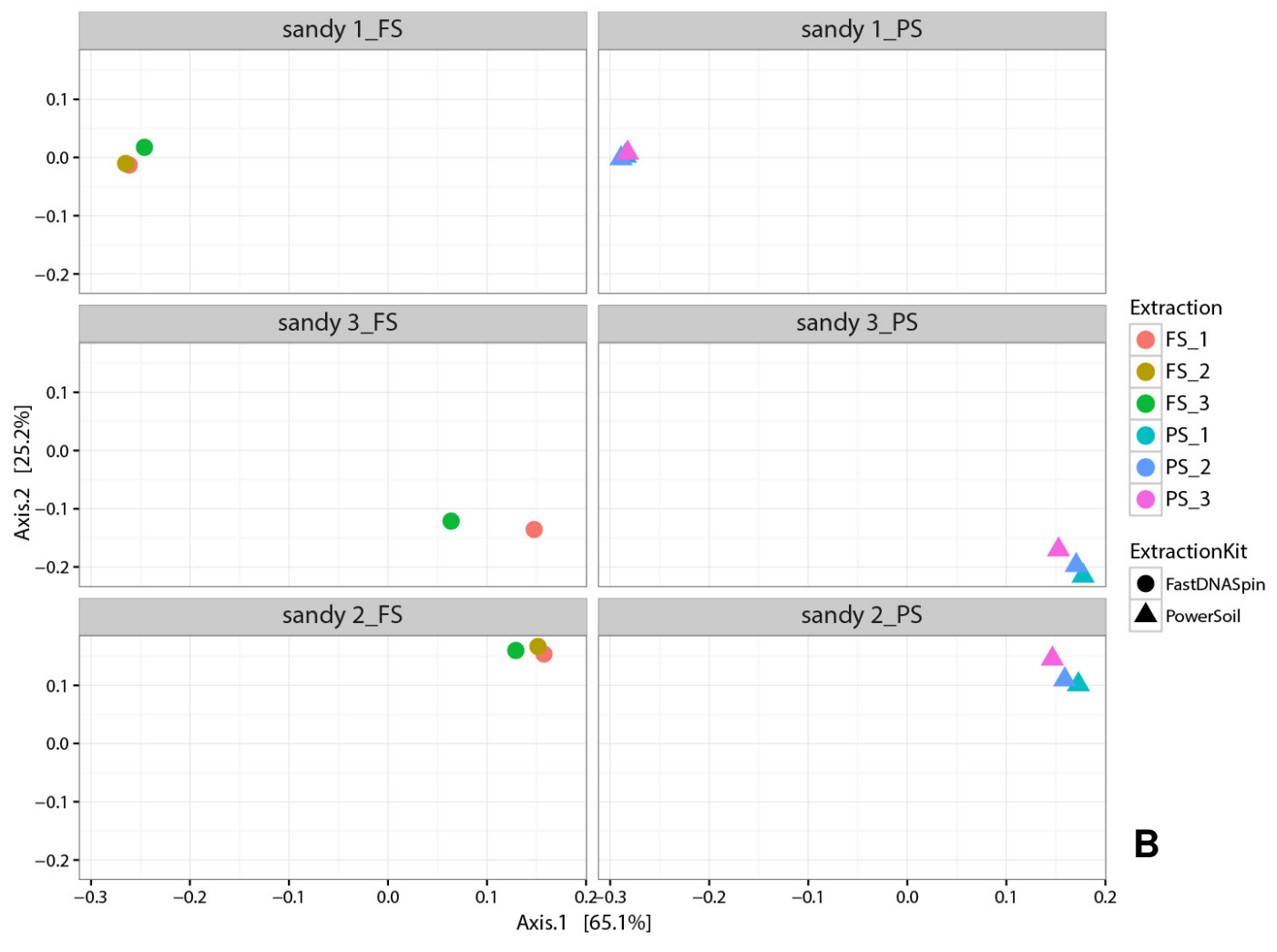

904

905 Figure 9. Multidimensional scaling (MDS) analysis of weighted Unifrac values from 906 fungal community in clay (A) and sandy soils (B). 

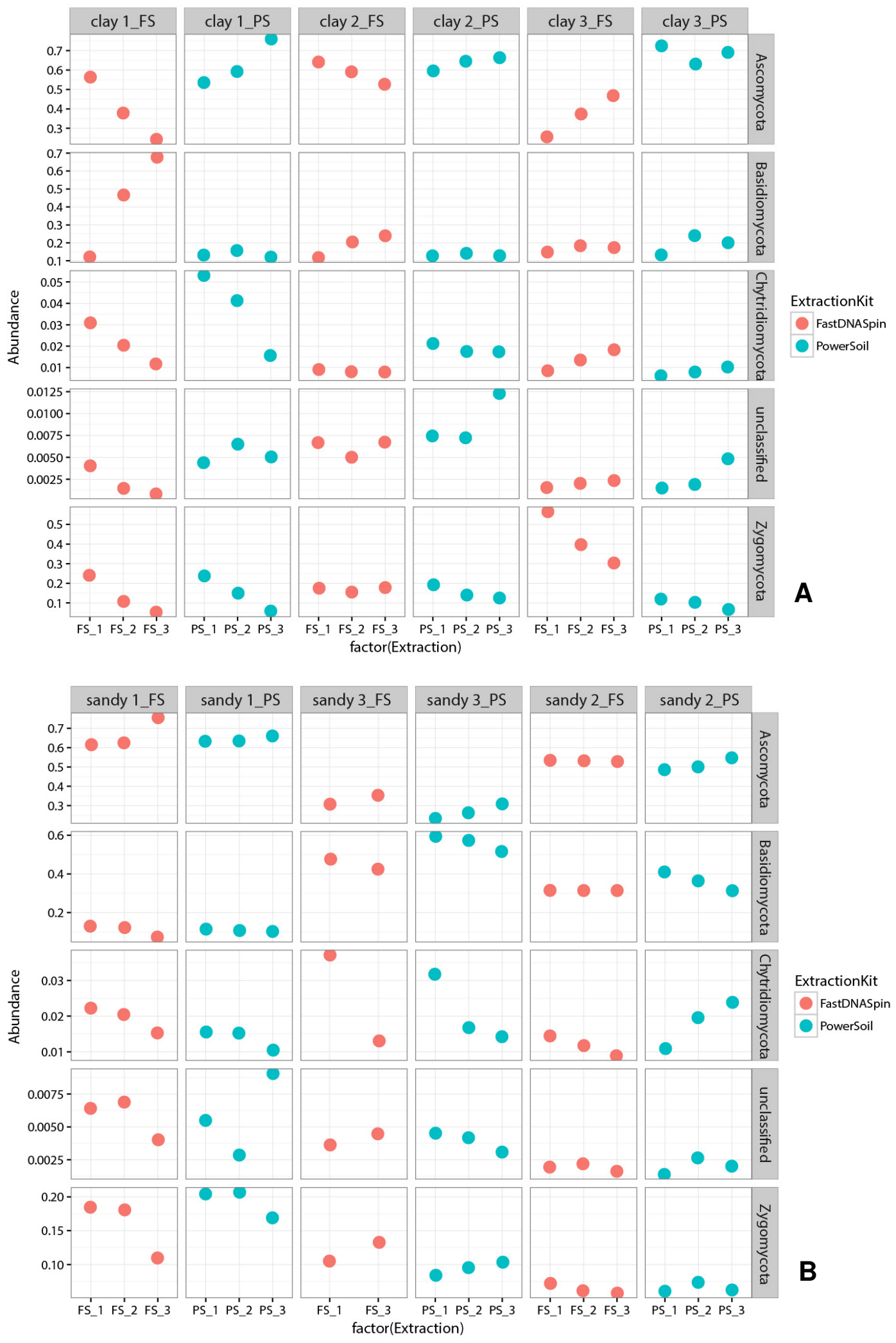

909 Figure 10. Relative abundance of the five most abundant fungal taxa found in clay

910 (A) and sandy (B) soils. Abundance is depicted as percentage, where one (1.0)

911 corresponds to the sum of all taxa found. 